\title{
MIPAS observations of longitudinal oscillations in the mesosphere and the lower thermosphere: climatology of odd-parity daily frequency modes
}

\author{
Maya García-Comas ${ }^{1}$, Francisco González-Galindo ${ }^{1}$, Bernd Funke ${ }^{1}$, Angela Gardini ${ }^{1}$, Aythami Jurado-Navarro ${ }^{1}$, \\ Manuel López-Puertas ${ }^{1}$, and William E. Ward ${ }^{2}$ \\ ${ }^{1}$ Instituto de Astrofísica de Andalucía-CSIC, Granada, Spain \\ ${ }^{2}$ Department of Physics, University of New Brunswick, Fredericton, New Brunswick, Canada \\ Correspondence to: Maya García-Comas (maya@iaa.es)
}

Received: 31 December 2015 - Published in Atmos. Chem. Phys. Discuss.: 25 February 2016

Revised: 26 July 2016 - Accepted: 15 August 2016 - Published: 6 September 2016

\begin{abstract}
MIPAS global Sun-synchronous observations are almost fixed in local time. Subtraction of the descending and ascending node measurements at each longitude only includes the longitudinal oscillations with odd daily frequencies $n_{\text {odd }}$ from the Sun's perspective at 10:00. Contributions from the background atmosphere, daily-invariant zonal oscillations and tidal modes with even-parity daily frequencies vanish. We have determined longitudinal oscillations in MIPAS temperature with $n_{\text {odd }}$ and wavenumber $k=0-4$ from the stratosphere to $150 \mathrm{~km}$ from April 2007 to March 2012. To our knowledge, this is the first time zonal oscillations in temperature have been derived pole to pole in this altitude range from a single instrument. The major findings are the detection of (1) migrating tides at northern and southern high latitudes; (2) significant $k=1$ activity at extratropical and high latitudes, particularly in the Southern Hemisphere; (3) $k=3$ and $k=4$ eastward-propagating waves that penetrate the lower thermosphere with a significantly larger vertical wavelength than in the mesosphere; and (4) a migrating tide quasi-biennial oscillation in the stratosphere, mesosphere and lower thermosphere. MIPAS global measurements of longitudinal oscillations are useful for testing tide modeling in the mesosphere and lower thermosphere region and as a lower boundary for models extending higher up in the atmosphere.
\end{abstract}

\section{Introduction}

The atmospheric solar tides (referred to as tides hereafter) are one of the most prominent and enduring dynamic features of the mesosphere and lower thermosphere (MLT). They are oscillations with periods that are subharmonics of a solar day. A case in point is that of the migrating tides, which are westward-propagating oscillations with a phase speed equal to the Earth's angular velocity, $\Omega$. They give the appearance of traveling with the Sun, dependent on the local solar time (LST) but not on longitude. Migrating tides are excited by a longitude-independent source, such as the absorption of solar IR radiation by water vapor in the troposphere, the solar UV radiation absorption by ozone in the stratosphere, and the local solar UV and EUV radiation absorption by oxygen molecules and atoms, respectively, and possibly by chemical heating (Smith et al., 2003), in the thermosphere.

The non-migrating tides also have periods which are subharmonics of a solar day, but they may be either westwardor eastward-propagating, or even stationary, and their phase speed is not $\Omega$. They are excited by longitudinally varying properties, like tropospheric latent heat release from evaporation, the Sun's gravitational pull, heating rates, and by nonlinear wave-wave interactions. An interaction between zonal wavenumber $s$ asymmetries in surface or atmospheric properties and the absorption of the $n$th harmonic of the diurnally varying solar radiation generates a sum and a difference tide with frequency $n \Omega$ and zonal wavenumbers $n \pm s$. For example, the zonally asymmetric latent heat release in the tropical troposphere caused by the wavenumber- 4 land-sea distribu- 
tion modulates the migrating diurnal DW1 component to excite the DE3 and DW5 tidal pair (Hagan and Forbes, 2002; Zhang et al., 2006). As an example of wave-wave interactions, involving tides and planetary waves, the interaction of the stationary planetary wave-1 sPW1 with DW1 leads to the formation of D0 and DW2 tidal modes (Hagan and Roble, 2001; Mayr et al., 2005a; Lieberman et al., 2015). Note that the widely used three-character notation for tides is also used here. The first letter corresponds to the daily frequency (D corresponds to diurnal, $\mathrm{S}$ corresponds to semidiurnal, and $\mathrm{T}$ corresponds to terdiurnal). The second letter indicates the direction of propagation ( $\mathrm{W}$ for westward and $\mathrm{E}$ for eastward). The number is the absolute value of the tide zonal wavenumber.

Tides also interact with other waves. Tidal interannual variability is correlated with the El Niño-Southern Oscillation (ENSO) (Gurubaran et al., 2005; Lieberman et al., 2007) and the wind quasi-biennial oscillation (QBO) (McLandress, 2002; Mayr and Mengel, 2005; Xu et al., 2009; Oberheide et al., 2009; Davis et al., 2013; Laskar et al., 2016); planetary and gravity wave (GW) activity may affect tidal activity (Fritts and Vincent, 1987; Teitelbaum and Vial, 1991; Mayr et al., 2005b; Pedatella and Liu, 2012; Ribstein et al., 2015); GW and tidal nonlinear interaction significantly affects winds (Liu et al., 2014). Nevertheless, there is no complete understanding of how these processes take place. For example, it is not clear whether the mesospheric QBO signature originates at stratospheric levels, locally in the mesosphere, or both (Oberheide et al., 2009).

Tides often propagate upwards. Regardless of the location of its source, the amplitude of upward-propagating tides increases with altitude, due to energy conservation in an environment of decreasing-with-altitude density. The tides that originate in the troposphere and propagate vertically connect the lower, middle and upper atmospheres. They also produce a second-order impact on atmospheric vertical coupling as they modulate the upward propagation of other waves, like gravity waves (Eckermann and Marks, 1996; Senf and Achatz, 2011). The connection also extends in the latitudinal direction because tides become a global feature under its standing wave latitudinal structure.

Over the last two decades, much progress has been made in determining the extent to which tides propagate from the lower atmosphere to the ionosphere, as well as how changes in lower altitude regions are transmitted by tides to the upper atmosphere or to other latitudes, but this knowledge is still incomplete. In this context, the lower thermosphere, in particular the E region, is of interest. Vertically propagating tides maximize at those altitudes, where molecular dissipation dominates (Forbes and Garrett, 1979). They impact the spatial and temporal variability through electrodynamical effects, and are transmitted even higher (Immel et al., 2006; Kil et al., 2007; Hagan et al., 2007; Jin et al., 2008; Pedatella et al., 2008; Scherliess et al., 2008; Häusler and Lühr, 2009; Forbes et al., 2009).
Several authors have studied tides from satellite measurements in this altitude region in recent years. The analyses are based on observations of wind fields (see, e.g., Oberheide and Forbes, 2008a; Talaat and Lieberman, 2010; Lieberman et al., 2013; Cho and Shepherd, 2015) or atmospheric species emission rates or abundances (see, e.g., Oberheide and Forbes, 2008b; Shepherd, 2011; Oberheide et al., 2013; Nee, 2014) or the ionized atmosphere (see, e.g., England et al., 2006; Chu et al., 2009; Mukhtarov and Pancheva, 2011). Few global observations of the neutral atmosphere are available in the $100-150 \mathrm{~km}$ altitude range. Temperatures have generally been analyzed at the lowest altitudes of this range (generally below $115 \mathrm{~km}$ ) using TIMED, Aura or WINDII satellite measurements (see, e.g., Wang et al., 2000; Forbes and Wu, 2006; Xu et al., 2009; Pancheva et al., 2010, 2013; Pancheva and Mukhtarov, 2011; Yue et al., 2013; Truskowski et al., 2014; Lieberman et al., 2015), or above the range, using WINDII measurements around $250 \mathrm{~km}$ (Shepherd et al., 2012) and CHAMP measurements of the exosphere (see e.g., Forbes et al., 2008, 2014; Oberheide et al., 2009; Bruinsma and Forbes, 2010). Studies of longitudinal oscillations measured by MIPAS on Envisat for this altitude range have been conducted by Xu et al. (2013), but only for selected atmospheric conditions (aurorae). The global temperature tidal spectrum is therefore not very well known at $100-150 \mathrm{~km}$. In addition to an understanding of the local behavior, observations at these altitudes are needed to discern the origin of longitudinal oscillations higher up in the atmosphere. Characterizing the non-migrating temperature tides there is relevant as this range constitutes the lower boundary in numerical models.

The Michelson Interferometer for Passive Atmospheric Sounding (MIPAS) (Fischer et al., 2008) measured the Earth's temperature from pole to pole, covering altitudes from 20 to $170 \mathrm{~km}$ on board a Sun-synchronous satellite, Envisat, offering the rare opportunity to observe longitudinal oscillations globally in this altitude range from a single instrument. MIPAS wide spatial and temporal coverages are ideal for constraining tidal vertical and latitudinal extent and global variations in seasonal and interannual timescales. Additionally, they may reveal indicators for the tidal excitation mechanisms, the processes inducing tidal variability and the lower and upper atmosphere coupling through tides. Additionally, the characterization of the tides in an atmospheric measurement dataset is a prerequisite for estimating trends (Beig et al., 2003).

The analysis of tides from atmospheric measurements is complex. Ideally, a complete longitudinal and local time coverage is needed in order to isolate the tidal components contributing to the observed signal. Sun-synchronous observations at $12 \mathrm{~h}$ intervals at fixed local times, like MIPAS, do not provide good local time coverage, but the combination of the measurements made in each node reduces aliasing (Oberheide et al., 2002; Lieberman et al., 2015). Non-Sunsynchronous observations allow for the separation of individ- 
ual tidal components but the slow satellite precession period generally worsens the temporal resolution (e.g., Zhang et al., 2006; Gan et al., 2014; Truskowski et al., 2014).

This work describes the longitudinal oscillations in temperature measured by MIPAS from 40 to $150 \mathrm{~km}$ over a 5 year period (March 2007-March 2012). With the benefit of the Sun-synchronous observational strategy, we extract the longitudinal wavenumbers as viewed by an observer of the Sun that is capable of isolating daily frequency parities. This paper describes the observed temperature oscillations with odd-parity daily frequencies.

The paper is organized as follows. Section 2 describes the MIPAS temperature observations used in this work. Monthly climatologies of the observed longitudinal wavenumbers are presented in Sect. 3, where we discuss their latitude, altitude and seasonal behavior in the context of other measurements. Section 4 includes a description of the interannual variability in the main oscillations. We end with a summary of the main findings. Appendix A includes a description of the method used.

\section{The instrument, dataset and error sources}

MIPAS measurements have full global coverage and were taken for the descending and ascending nodes at approximately two fixed local times, 10:00 and 22:00 (in general, local times differ from the average values by less than half an hour at latitudes equatorward of $75^{\circ}$ and by three quarters of an hour equatorward of $85^{\circ}$ ). The MIPAS Middle Atmosphere (MA) and Upper Atmosphere (UA) modes of observation resulted in an altitude coverage of 18-102 and 40$170 \mathrm{~km}$, respectively (Oelhaf, 2008). While operating with optimized resolution $\left(0.0625 \mathrm{~cm}^{-1}\right.$; unapodized $)$, full day observations using these modes were performed regularly (approximately 1 day in each mode every 10 days) from April 2007 to March 2012, thus covering 5 years.

MIPAS spectra range from 4.3 to $15.6 \mu \mathrm{m}$. Temperature and line-of-sight (LOS) information are derived in the MLT region from the $15 \mu \mathrm{m} \mathrm{CO} 2$ emission using the IMK/IAA scientific MIPAS level 2 processor described in von Clarmann et al. (2009), which accounts for non-LTE effects using the GRANADA model (Funke et al., 2012). In this study we use data versions V5R_TLOS_521 and V5R_TLOS_621 of MA and UA, respectively, retrievals (García-Comas et al., 2014), which provide temperature profiles with a vertical resolution of 3 to $10 \mathrm{~km}$, from the stratosphere up to around $110 \mathrm{~km}$ $\left(T_{\mathrm{MLT}}\right)$ (García-Comas et al., 2012; IMK-IAA MIPAS team, 2016).

Thermospheric temperatures ( $T_{\mathrm{THER}}$ ) from 115 up to $150 \mathrm{~km}$ are derived from MIPAS $5.3 \mu \mathrm{m}$ NO emission measurements in the UA mode with a vertical resolution of 10$15 \mathrm{~km}$ (Bermejo-Pantaleón et al., 2011). We use retrieval version V5R_TT_621 of $T_{\text {THER }}$ (IMK-IAA MIPAS team, 2016). This version differs from that described in Bermejo-
Pantaleón et al. (2011) in the spectra calibration version supplied by the ESA and in the use of NOEM (Nitric Oxide Empirical Model) day and night concentrations (Marsh et al., 2004) as a priori, which correct artifacts affecting nighttime temperatures. Tests have showed that this temperature version leads to nighttime zonal mean temperature structures that are similar but smaller in absolute value by $10-15 \mathrm{~K}$ below $140 \mathrm{~km}$ and $15-25 \mathrm{~K}$ above $140 \mathrm{~km}$.

MIPAS temperature systematic errors are significant (1$3 \mathrm{~K}$ below $85 \mathrm{~km}$ and $3-10 \mathrm{~K}$ above $85 \mathrm{~km}$ for $T_{\mathrm{MLT}}$, and $10-20 \mathrm{~K}$ for $T_{\text {THER }}$ ), but as we analyze differences of longitudinal perturbations about an average value (see Sect. A), biases often partially cancel out, so that their effect on the derived oscillation characteristics is small. Additionally, we work with monthly averages, which reduce the random error by at least a factor of $1 / \sqrt{3}$. One of the most significant errors we expect is that produced by the limited vertical resolution. At the peaks of a vertical wave, the wave amplitude error due to that smoothing depends on its vertical wavelength. Smoothing errors are 2-5\% in the mesosphere, $15 \%$ around $120 \mathrm{~km}$ and $30 \%$ around $140 \mathrm{~km}$ for $25 \mathrm{~km}$ vertical wavelength waves. They increase for short vertical wavelengths, reaching 15-30\% in the mesosphere and $60 \%$ around $120 \mathrm{~km}$ for $10 \mathrm{~km}$ vertical wavelength waves.

The temperature retrieval algorithm uses a priori information of the temperature at each MIPAS geolocation taken from ECMWF at pressures larger than $0.1 \mathrm{hPa}(\approx 70 \mathrm{~km})$ and merged with NRLMSISE-00 model results at lower pressures. NRLMSISE-00 includes only effects of low-order tides (Picone et al., 2002). We examined a priori temperature oscillations with longitude in the fixed local time frame of MIPAS. Besides the migrating component, we only detect wavenumber-1 and 2 non-migrating zonal oscillations with amplitudes generally smaller than $1 \mathrm{~K}$. Some exceptions occur in the winter high latitudes, probably corresponding to planetary wave activity (wavenumber- 1 structures reaching $10 \mathrm{~K}$ at $40 \mathrm{~km}, 5 \mathrm{~K}$ at $50 \mathrm{~km}$ and $2 \mathrm{~K}$ at $75 \mathrm{~km}$ ). Given the differences between measurement and a priori tidal component fields (see Sect. 3.1), we conclude that the mapping of a priori longitudinal oscillations on the retrievals is not significant and does not influence MIPAS temperatures.

\section{Five-year average zonal oscillations}

Following the procedure described in Appendix A, we derived amplitudes and phases of the longitudinal oscillations of apparent wavenumber $k$ from the stratosphere to the lower thermosphere as seen in MIPAS temperature differences of the descending and the ascending nodes.

We have constructed longitude-altitude maps of monthly $T_{\text {MLT }}$ and $T_{\text {THER }}$ temperatures averaged from April 2007 to March 2012 for the descending and the ascending legs. In order to achieve a good longitudinal coverage with a small loss of horizontal resolution, we used longitude and latitude 

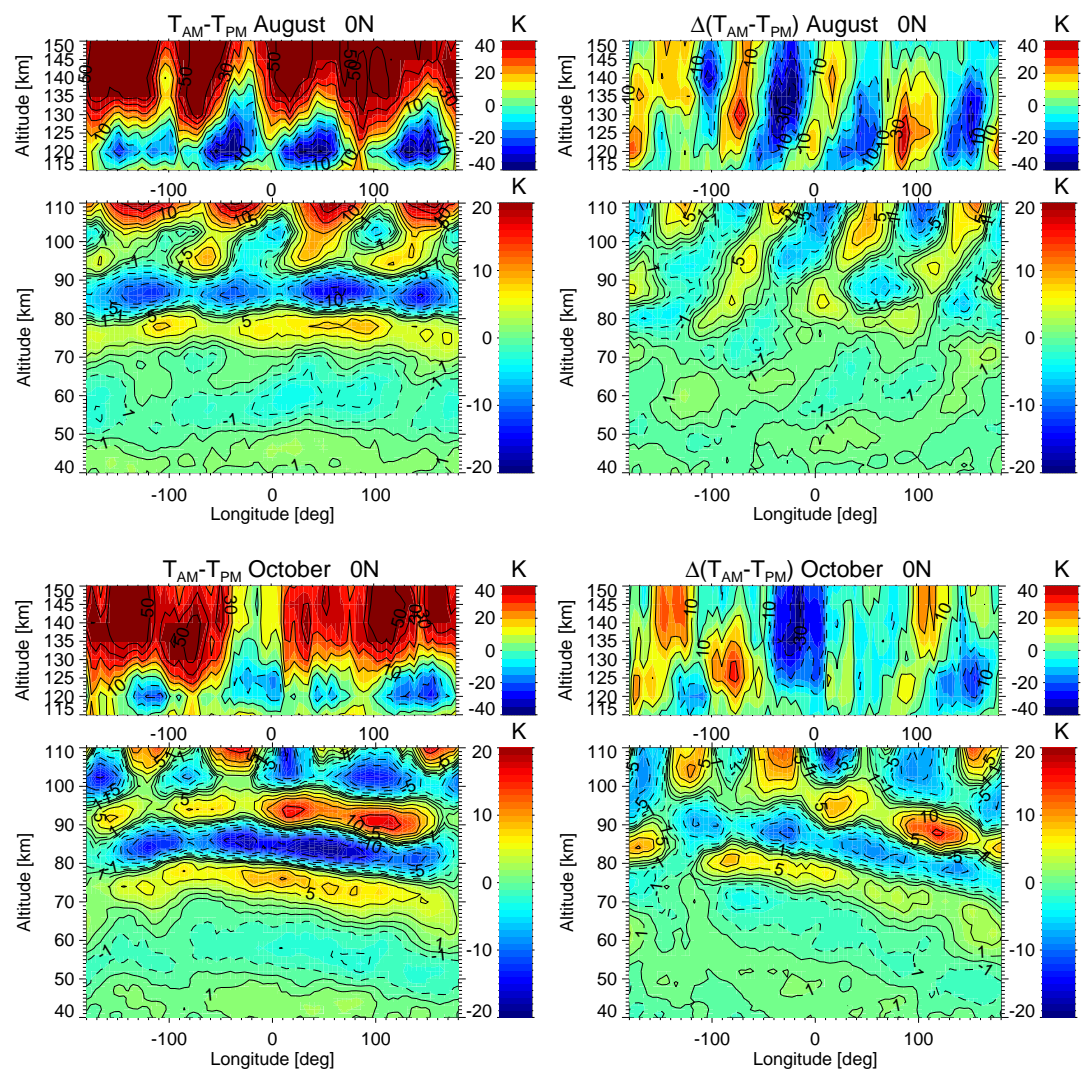

Figure 1. Equatorial MIPAS monthly mean temperature difference (left) and anomaly (with respect to the mean value at each altitude; right) of $\Delta T / 2$ for August (first and second rows) and October (third and fourth rows) averaged for 2007-2012. Temperatures below 110 km are retrieved from measurements at $15 \mu \mathrm{m}$ and above $115 \mathrm{~km}$ from $5.3 \mu \mathrm{m}$. Note the different color scales.

running means at each altitude in a $5^{\circ} \times 5^{\circ}$ grid. At each grid point, we averaged MIPAS monthly measurements taken within $25^{\circ}$ in longitude and $10^{\circ}$ in latitude bins. We then subtracted and divided by 2 the descending and the ascending node measurements at each grid point, denoted $\Delta T / 2$ hereafter.

Figure 1 left panels show typical $\Delta T / 2$ fields. They are August and October monthly means averaged over the 5 years and constructed from $T_{\mathrm{MLT}}$ and $T_{\mathrm{THER}}$ measurements over the Equator. A background with alternating positive and negative horizontal stripes is evident. A longitudeindependent signature at each altitude must be responsible for that pattern. A longitude-independent feature in $\Delta T / 2$ corresponds to a migrating component. The pattern is stronger during October (equinox) than August (solstice). Vertically alternating $\Delta T / 2$ maxima and minima correspond to altitudes where the tidal phase is at 10:00 $(45,75,95$ and $110 \mathrm{~km})$ and 22:00 $(60,85105$ and $120 \mathrm{~km})$, respectively. A different regime takes place above $125 \mathrm{~km}$, where a background positive $\Delta T / 2$ remains nearly constant with altitude. This implies a nearly constant-with-altitude LST phase - that is, the oscillation does not propagate vertically. This is typical of an in situ-generated oscillation.
Table 1. Main tidal component contributions resolved in our spectral analysis. The derived amplitudes and phases are a combination of all modes contributing.

\begin{tabular}{lll}
\hline$n$ & $\begin{array}{l}\text { Wavenumber } \\
|n-s|\end{array}$ & Components \\
\hline odd & 0 & DW1 + TW3 \\
& 1 & D0 + DW2 + TW2 \\
& 2 & DW3 + DE1 + TW1 \\
3 & DE2 + DW4 + T0 \\
4 & DE3 + DW5 + TE1 \\
\hline
\end{tabular}

The right panels in Fig. 1 are $\Delta T / 2$ longitudinal anomalies (zonal mean subtracted at each altitude) averaged for $\mathrm{Au}-$ gust and October. They contain only $n_{\text {odd }}$ non-migrating tidal modes $\left(\left|n_{\text {odd }}-s\right|\right.$ larger than 0$)$. In August, a wavenumber-4 oscillation tilting eastward with height is noticeable from the mid-mesosphere to the thermosphere with increasing amplitude up to $130 \mathrm{~km}$. A subtle underlying wave-1 perturbation propagates to the west in the upper mesosphere but suffers efficient dissipation in the lowermost part of the thermosphere. 

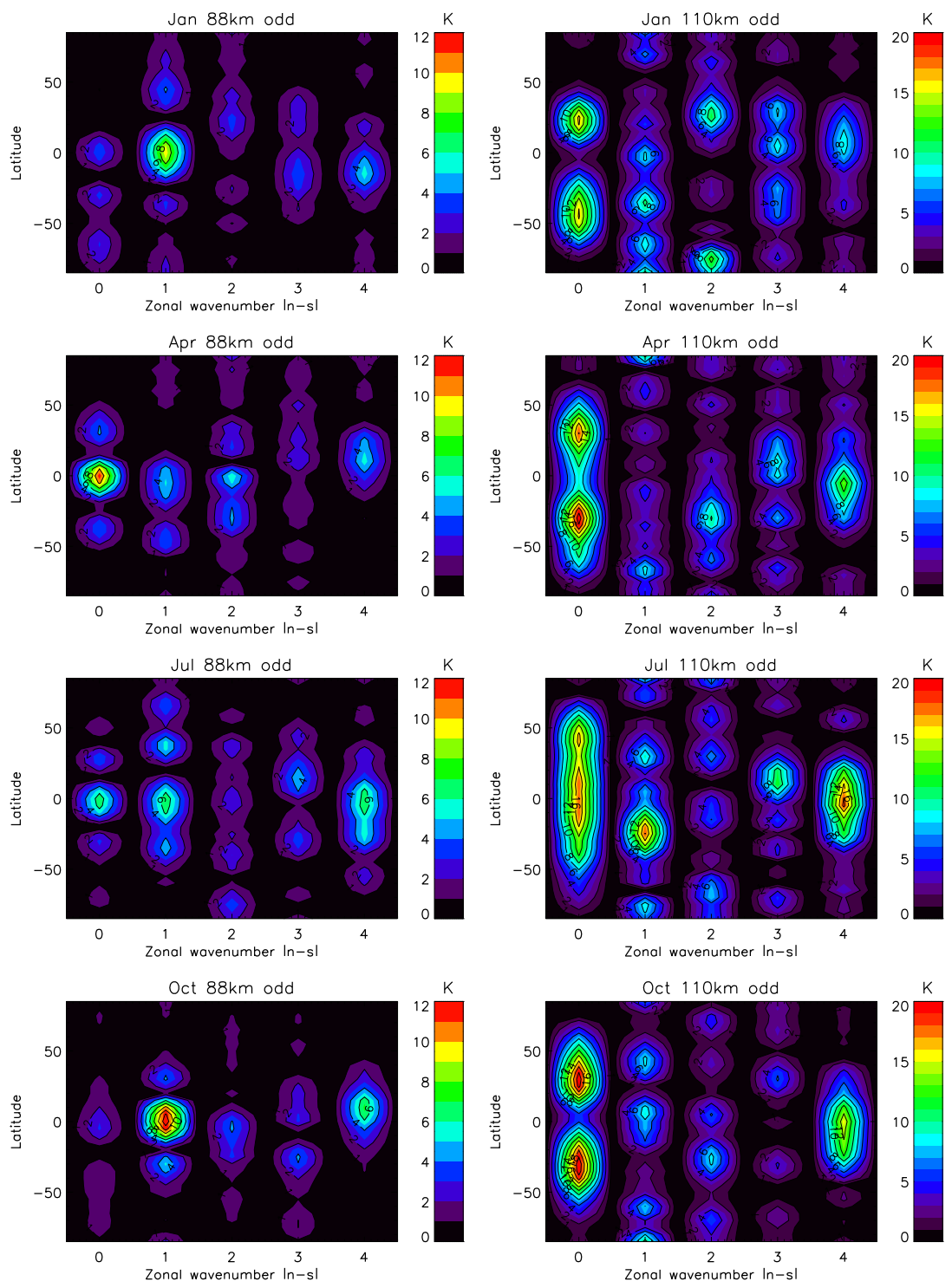

Figure 2. MIPAS $\Delta T / 2$ average (2007-2012) monthly mean spectra at $88 \mathrm{~km}$ (left) and $110 \mathrm{~km}$ (right) for January (first row), April (second row), July (third row) and October (fourth row). MIPAS zonal wavenumbers correspond to $\left|n_{\text {odd }}-s\right|$ of the daily frequency $n$ and the zonal wavenumber $s$ of comprised tidal modes (see Table 1).

The October $\Delta T / 2$ anomaly field in Fig. 1 exhibits wavenumber- 1 features tilting westward with height $(18 \mathrm{~km}$ vertical wavelength). This signature is noticeable from $40 \mathrm{~km}$ (in the stratosphere) and extends to $110 \mathrm{~km}$ (in the lower thermosphere). Its vertical and longitudinal structure is similar to the one in August but the October feature is significantly stronger. Starting at $105 \mathrm{~km}$, a zonal wavenumber-4 structure overlaps. This feature is perceived on the $T_{\text {THER }}$ fields above $115 \mathrm{~km}$ but it is not as evident as at lower altitudes or in August, probably because it is weak and/or another component overlaps.

We performed the spectral analysis of MIPAS $\Delta T / 2$ fields analogous to those shown in Fig. 1 globally and for the 12 months of the calendar year (see Appendix A). For each altitude $z$, latitude $\phi$ and month, we derived amplitudes $C_{k}$ and phases $\theta_{k}$, for which $k$ are the apparent longitudinal wavenumbers in $\Delta T / 2$ that embed the combination of the tidal modes with odd-parity daily frequency $n$ and zonal wavenumber $s$ such that $|n-s|=k$. We hereafter denote this combined oscillation by $\left|n_{\text {odd }}-s\right|=k$. Table 1 summarizes the major tidal components contributing to each apparent zonal wavenumber.

Positive and negative wavenumbers, indicating horizontal direction of propagation, cannot be separated in the spectra. Nevertheless, if the direction of vertical propagation is known, the dependence of the phases $\theta_{k}$ on altitude ulti- 

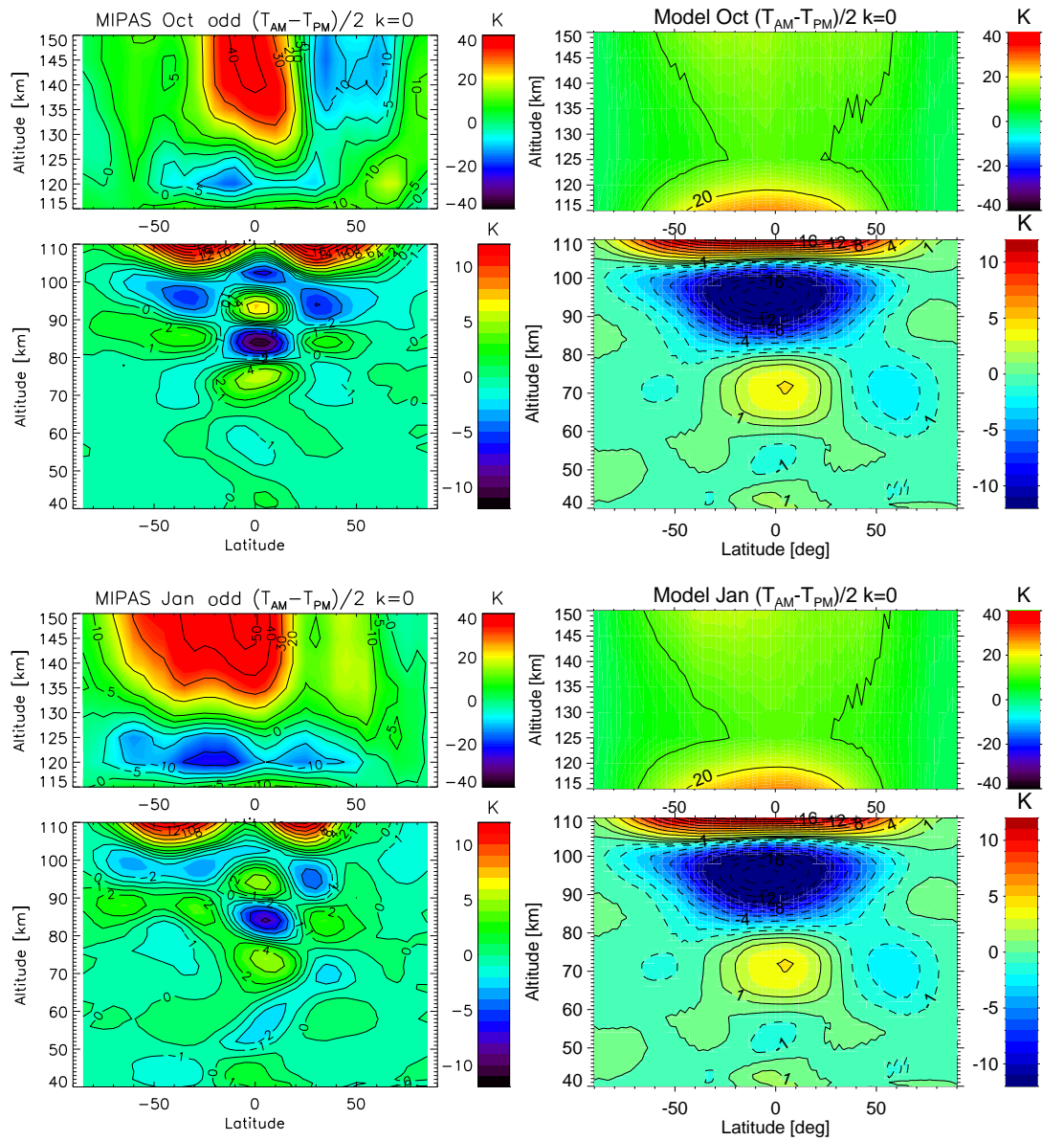

Figure 3. Zonal means of $\Delta T / 2\left(\left|n_{\text {odd }}-s\right|=0\right.$ mode, embedding DW1 and TW3) extracted from average (2007-2012) monthly means of MIPAS $T_{\text {MLT }}(20-110 \mathrm{~km})$ and $T_{\text {THER }}(115-150 \mathrm{~km})$ temperatures (left) compared to corresponding zonal means of the a priori (ECMWF and NRLMSISE-00; see text) (right), for October (first and second rows) and January (third and fourth rows).

mately helps discern dominance of a particular tidal mode. For instance, assuming upward propagation, a $\theta_{k}$ moving to the east (west) with increasing altitude corresponds to an eastward-propagating (westward-propagating) tidal oscillation if $s=n-k<0(s=n+k>0)$.

Figure 2 shows the derived average amplitude spectra during equinox months (April and October) and solstice months (January and July) at 88 and $110 \mathrm{~km}$ from wavenumber 0 to 4. The dominance of some modes is evident and depends on season and altitude.

For latitudes within $45^{\circ} \mathrm{N}$ and $45^{\circ} \mathrm{S}$, the $\left|n_{\text {odd }}-s\right|=0$ mode is the strongest component in the upper mesosphere and below $100 \mathrm{~km}$ during April (and also February, March, May and August; not shown). Its amplitude ranges from 9 to $18 \mathrm{~K}$. The $\left|n_{\text {odd }}-s\right|=1$ and $\left|n_{\text {odd }}-s\right|=4$ oscillations follow in importance. During January and October (and also September, November and December; not shown), wavenumber $\left|n_{\text {odd }}-s\right|=1$ is the dominating component of the tidal field $(8-15 \mathrm{~K})$ in the mesosphere. In July (and June; not shown), wavenumber $\left|n_{\text {odd }}-s\right|=4$ is the most important
(8 K), although $\left|n_{\text {odd }}-s\right|=0,1$ have similar amplitudes. MIPAS also detects $\left|n_{\text {odd }}-s\right|=0,1$ oscillations around $60-70^{\circ}$ during the summers with $2 \mathrm{~K}$ amplitudes.

In the lower thermosphere, around $110 \mathrm{~km}$, the strongest $n_{\text {odd }}$ longitudinal oscillation in MIPAS data is $\left|n_{\text {odd }}-s\right|=0$ at latitudes smaller than $70^{\circ}$ and also $\left|n_{\text {odd }}-s\right|=4$ at latitudes smaller than $40^{\circ}$ (see Fig. 2). This happens throughout the year, with the former peaking around $25^{\circ} \mathrm{N}$ and $\mathrm{S}$ (15$20 \mathrm{~K})$ (except during June and July) and the latter over the Equator (8-16 K). In July and August, the $\left|n_{\text {odd }}-s\right|=4$ oscillation stands out particularly and wavenumber $\left|n_{\text {odd }}-s\right|=$ $1(15 \mathrm{~K})$ is then also noticeable at $25^{\circ}$. At the highest latitudes, $\left|n_{\text {odd }}-s\right|=1$ is the only significant mode, although signatures from $\left|n_{\text {odd }}-s\right|=2$ oscillations are also present, for example, in January (12 K).

Next, we five a detailed description of each of the extracted longitudinal oscillation modes and their seasonal variations. The MIPAS Sun-synchronous view provides a fixed local time shot of longitudinal variations. If otherwise not indicated, we use a phase defined in terms of longitude (positive 

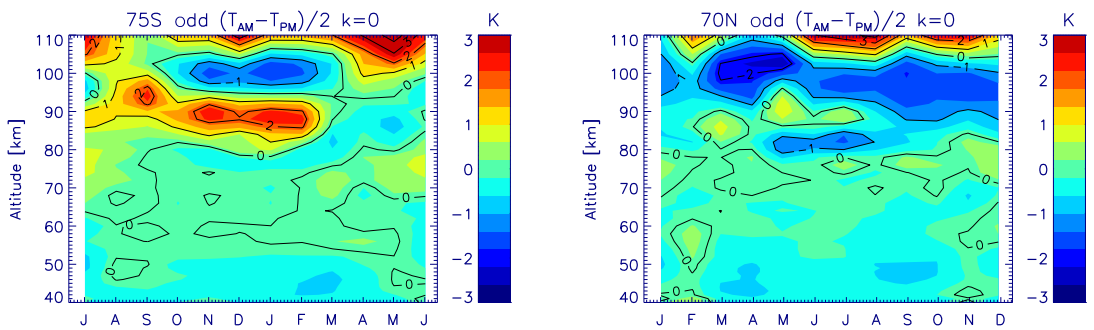

Figure 4. Time series of the vertical distribution of average (2007-2012) $\Delta T / 2$ monthly zonal means $\left(\left|n_{\text {odd }}-s\right|=0\right.$ mode) at high latitudes $\left(75^{\circ} \mathrm{S}\right.$, left; $75^{\circ} \mathrm{N}$, right).

towards the east of Greenwich) of maximum at 10:00. The caveat is that the phase is undefined for longitudinally standing tidal components $(s=0)$.

\subsection{The $\left|n_{\text {odd }}-s\right|=0$ mode}

The $\left|n_{\text {odd }}-s\right|=0$ mode, which is just the $\Delta T / 2$ zonal mean, contains contributions from the diurnal (DW1) and terdiurnal (TW3) migrating tides. Figures 3-5 include representative latitude-altitude and latitude-time cross sections. Because MIPAS observations occur at two fixed local times, contributions from migrating tides (which depend only on local time) are seen as invariant features over longitude. The values measured correspond to the temperature perturbations produced by these migrating tides at 10:00. These do not directly correspond to tidal amplitudes at altitudes where the vertical profiles do not peak.

Temperature difference maps of 10:00-22:00 for DW1 and TW3 from ECMWF at altitudes below around $0.1 \mathrm{mb}$ and NRLMSISE-00 above, used as a priori (see Sect. 2), are also shown in Fig. 3. The aim of this comparison is to verify that the retrieved vertical structures are not merely those transferred from the a priori.

MIPAS $\left|n_{\text {odd }}-s\right|=0$ latitude-altitude cross section below $120 \mathrm{~km}$ exhibits maximum absolute values over the Equator and at $35^{\circ} \mathrm{N}$ and $35^{\circ} \mathrm{S}$ in October (Fig. 3). Peaks of alternating sign are located at the Equator at $42 \mathrm{~km}(1 \mathrm{~K}), 56 \mathrm{~km}$ $(-1 \mathrm{~K}), 74 \mathrm{~km}(5 \mathrm{~K}), 84 \mathrm{~km}(-11 \mathrm{~K}), 94 \mathrm{~km}(7 \mathrm{~K}), 104 \mathrm{~km}$ $(-6 \mathrm{~K}), 110 \mathrm{~km}(12 \mathrm{~K})$ and $120 \mathrm{~km}(-20 \mathrm{~K})$. Out-of-phase peaks (opposite sign) occur at $35^{\circ}$ below $105 \mathrm{~km}$. Their altitudes in the Northern Hemisphere (NH) are similar to those at the Equator, but they are $2 \mathrm{~km}$ higher in the Southern Hemisphere $(\mathrm{SH})$. These extratropical perturbations are weaker ( $<1 \mathrm{~K}$ below $80 \mathrm{~km}$ and $2 \mathrm{~K}$ at $84 \mathrm{~km},-6 \mathrm{~K}$ at $94 \mathrm{~km}, 4 \mathrm{~K}$ at $104 \mathrm{~km}$ and $15 \mathrm{~K}$ at $110 \mathrm{~km}$ ) than at the Equator.

The a priori migrating component also presents the largest perturbations for the equinoxes and over the Equator (Fig. 3). The alternating minima and maxima are located at similar altitudes below $70 \mathrm{~km}$ (corresponding to ECMWF), but the vertical wavelength above (NRLMSISE-00) increases and peaks are located only at $95 \mathrm{~km}$ and $110 \mathrm{~km}$. Out-of-phase weaker oscillations appear only at $60^{\circ} \mathrm{N}$ and $60^{\circ} \mathrm{S}$ at 70
$75 \mathrm{~km}$. This shows poor agreement between NRLMSISE00 and MIPAS but proves that MIPAS $\left|n_{\text {odd }}-s\right|=0$ does not come from the a priori. The Global Scale Wave Model (GSWM-09; Hagan and Roble, 2001; Zhang et al., 2010a, b) and the Climatological Tidal Model of the Thermosphere (CTMT; Oberheide and Forbes, 2008a; Oberheide et al., 2011b) DW1 sampled at MIPAS LT (not shown) present peaks located generally within $2-4 \mathrm{~km}$ and $1-2 \mathrm{~K}$ of those of MIPAS below $100 \mathrm{~km}$, except for the maxima at 70 and $95 \mathrm{~km}$ over the Equator (5-8 K smaller in MIPAS).

MIPAS oscillation exhibits a vertical wavelength decreasing with altitude, varying from $30 \mathrm{~km}$ around the stratopause to $20 \mathrm{~km}$ around $110 \mathrm{~km}$. This is comparable to $27 \mathrm{~km}$, the classical tidal theory prediction for $(1,1)$ (Chapman and Lindzen, 1970). The model DW1 has a slightly longer vertical wavelength on average than that given by MIPAS, particularly in the upper mesosphere. This could indicate caveats in the representation of gravity wave and tide interactions in this version of the model (Achatz et al., 2008). We note, however, that superposition of TW3 may affect the MIPASderived vertical wavelength.

The latitudinal structure of the phase changes above $105 \mathrm{~km}$. The perturbations from the tropics to $50^{\circ}$ around $110 \mathrm{~km}$, peaking at $35^{\circ}(15 \mathrm{~K})$, are not out of phase with those at the Equator. This is consistent with overlapping of TW3, with the most pronounced amplitudes at midlatitudes above $100 \mathrm{~km}$ (Moudden and Forbes, 2013; Yue et al., 2013), and/or the effect of the thermospheric in situ DW1 tide. This MIPAS feature is similar in NRLMSISE-00 but does not compare well with GSWM-09 or CTMT DW1 at $110 \mathrm{~km}$, which exhibit typical $(1,1)$ mode structure. We note that GSWM-09 and CTMT do not include in situ tidal forcing.

At $120 \mathrm{~km}$, MIPAS zonal mean temperature differences switch to negative values for latitudes between $50^{\circ} \mathrm{S}$ and $30^{\circ} \mathrm{N}$. There are several possibilities that might explain this feature. It could be due mainly to TW3. If related to a feature at $110 \mathrm{~km}$ explained by TW 3 contribution, it would imply a TW3 vertical wavelength of $20 \mathrm{~km}$. This is larger than expected from models (Du and Ward, 2010) but similar to TW3 wavelengths derived from previous measurements in the upper mesosphere (Thayaparan, 1997). Another possibility is a preferential dissipation of the low-order DW1 modes 

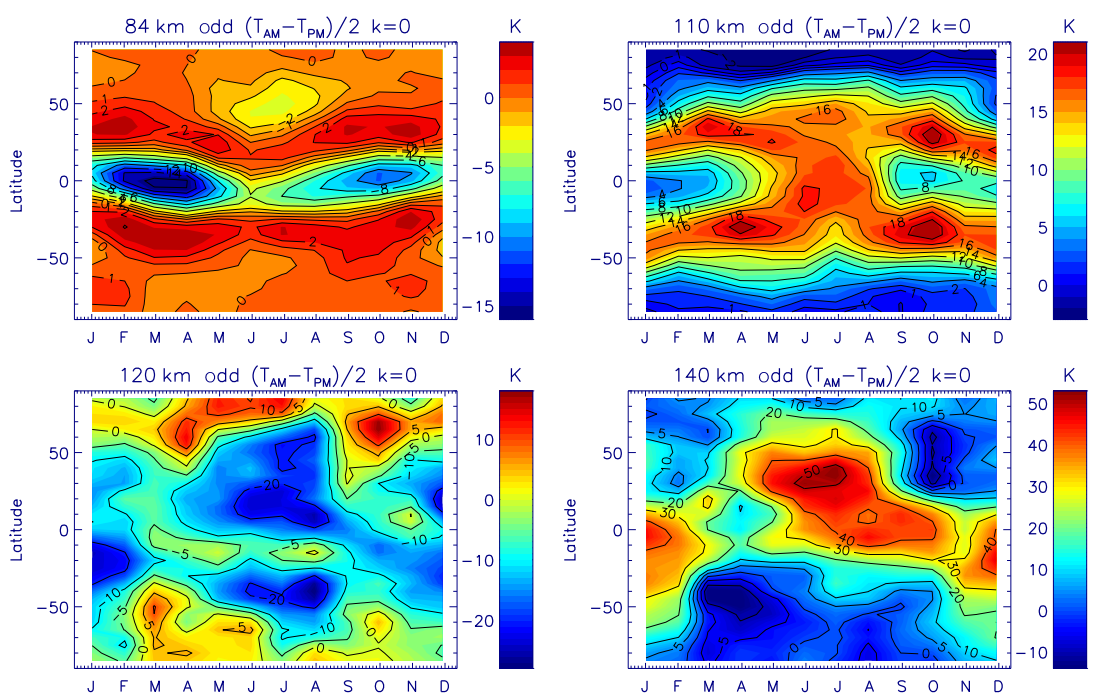

Figure 5. Time series of the latitudinal distribution of average (2007-2012) monthly zonal mean $\Delta T / 2\left(\left|n_{\text {odd }}-s\right|=0\right.$ mode) at 84,110 , 120 and $140 \mathrm{~km}$.

from the Hough Mode Extension (HME) (Forbes and Hagan, 1982) at lower altitudes so that higher-order modes dominate at these higher altitudes. Finally, it could also be a consequence of the thermospheric in situ DW1. The latter would imply a downward propagation of the thermospheric component, allowed under the thermosphere viscid regime (Forbes and Garrett, 1976).

The feature at $120 \mathrm{~km}$ is not identifiable in GSWM-09 and CTMT DW1 results at MIPAS LT sampling. It appears in neither NRLMSISE-00 nor the thermosphere extension of the Whole Atmosphere Community Climate Model (WACCMX) (Liu et al., 2010), which include in situ DW1. We cannot rule out that part of this disagreement is due to remaining artifacts in MIPAS $T_{\text {THER }}$ due to unrealistic a priori NO day/night abundances used in the retrievals (see BermejoPantaleón et al., 2011).

At $130-150 \mathrm{~km}$, MIPAS measures positive morningafternoon zonal mean differences at $35^{\circ} \mathrm{S}-25^{\circ} \mathrm{N}$ in October (Fig. 3). The nearly constant-with-altitude values above $130 \mathrm{~km}$ evidence no phase change with altitude. This is consistent with the effect of the thermospheric in situ-generated diurnal migrating component. The phase of the in situ thermospheric tide is $\varphi_{\text {DW } 1}=14: 00-16: 00$, dependent on the solar flux input (see, e.g., Forbes and Garrett, 1976; Liu et al., 2010). Since MIPAS measurements correspond to $L S T=10$, we note that MIPAS measurements of the thermosphere DW1 effect underestimate total in situ tide amplitudes by a factor of $\cos \left(n \Omega\left(10-\varphi_{\mathrm{DW} 1}\right)\right)$.

Comparison with NRLMSISE-00 shows little agreement at these altitudes. On the one hand, this strengthens the idea of the a priori having little impact on the derived temperature oscillations, but, on the other hand, MIPAS significantly overestimates the model predictions. Again, artifacts in MIPAS $T_{\text {THER }}$ retrieval cannot be ruled out.

Figure 3 also shows $\left|n_{\text {odd }}-s\right|=0$ longitudinal perturbations for January. Maximum and minimum values over the Equator and in the $\mathrm{NH}$ are slightly higher $(2 \mathrm{~km})$ and $2-3 \mathrm{~K}$ smaller than in October below $110 \mathrm{~km}$ at low to midlatitudes. In the thermosphere, negative perturbations at $120 \mathrm{~km}$ are $5 \mathrm{~K}$ stronger than in October. Above $130 \mathrm{~km}$, the signature of the in situ tide is clear $(10-50 \mathrm{~K})$, producing maximum perturbations off the Equator and tracking the subsolar point.

At southern high latitudes (55-75 $\mathrm{S})$, MIPAS sees an oscillation peaking at 90 and $100 \mathrm{~km}$ in January (Fig. 3). It is in phase with the perturbations at $35^{\circ}$, probably indicating that it belongs to a different HME. Its dependence with season is shown in the time series at $75^{\circ} \mathrm{S}$ and $70^{\circ} \mathrm{N}$ depicted in Fig. 4. A vertical perturbation peaking at 10:00 with alternating maxima and minima at 90,100 and $110 \mathrm{~km}$ is clearly seen from late spring through summer at $75^{\circ} \mathrm{S}(2 \mathrm{~K})$. This structure is also present at northern high latitudes $\left(70^{\circ} \mathrm{N}\right)$ at similar altitudes but with slightly weaker amplitudes. This detection corroborates previous measurements of temperature tides at southern high latitudes, where $3 \mathrm{~K}$ amplitude diurnal components with 10:00 phases were measured from the ground at around $90 \mathrm{~km}$ (Lübken et al., 2011). Here we detect a NH counterpart.

Latitude-time slices at altitudes where $\left|n_{\text {odd }}-s\right|=0$ generally peak $(84,110,120$ and $140 \mathrm{~km})$ are shown in Fig. 5. The seasonal and latitudinal variability is highly dependent on altitude. Starting with $84 \mathrm{~km}$, the perturbation is stronger during the equinoxes than during solstices. This is due to the influence of the seasonal variation of the symmetry of the heating source (Forbes et al., 2001) and the zonal winds in the middle atmosphere (McLandress, 2002; Zhu et al., 2005), 

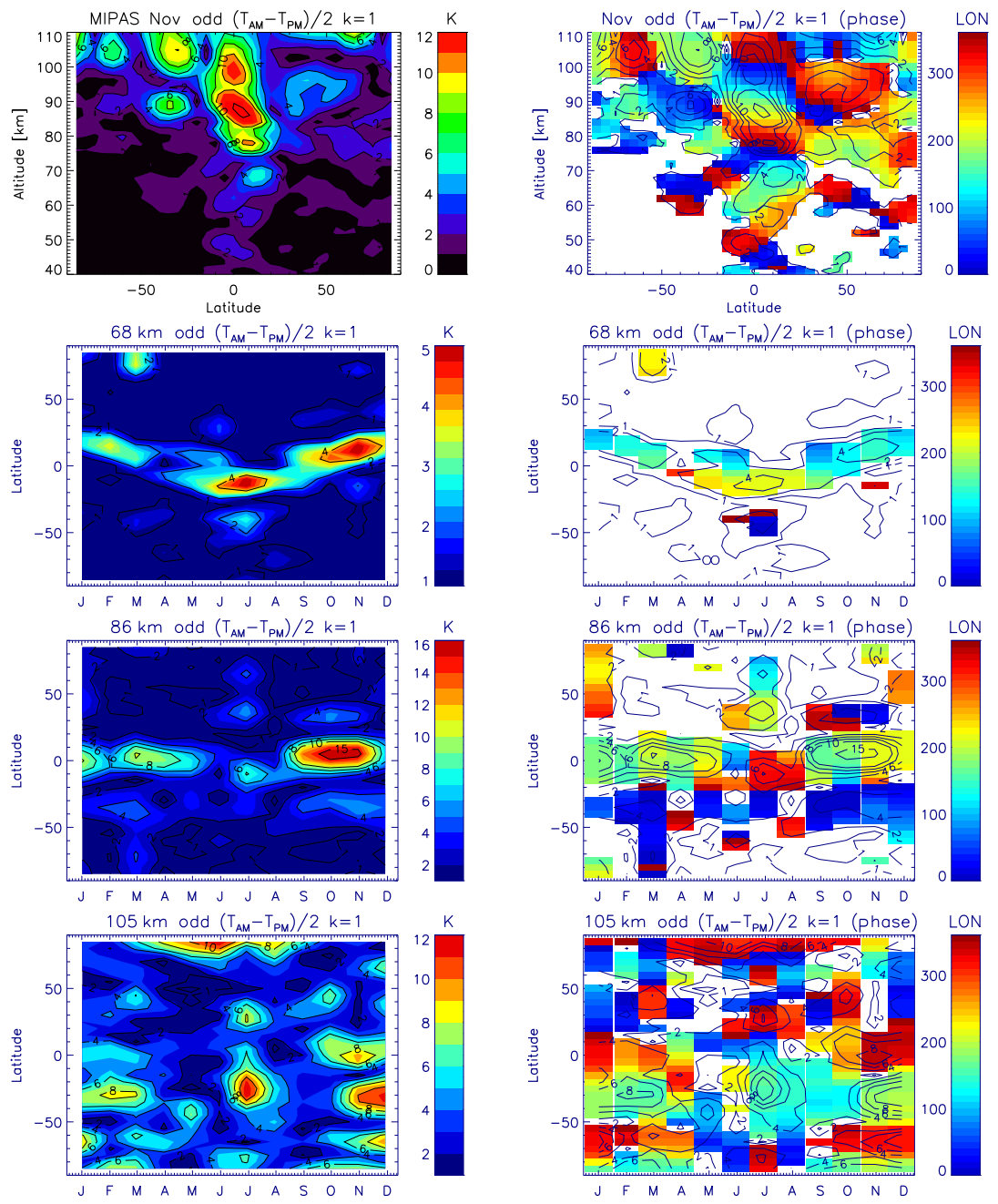

Figure 6. Latitude-altitude fields for November (first row) and latitude-time fields at 68,86 and $105 \mathrm{~km}$ (second-fourth rows) of amplitudes and phases of MIPAS average (2007-2012) $\left|n_{\text {odd }}-s\right|=1$ mode. D0, DW2 and TW2 tidal oscillations are embedded.

probably below $70 \mathrm{~km}$ (Achatz et al., 2008). Amplitudes are smaller than $1 \mathrm{~K}$ for latitudes larger than $70^{\circ}$ at this altitude.

At $110 \mathrm{~km}$, the perturbation is positive all year round, except north of $70^{\circ} \mathrm{N}$, and varies significantly $(2-15 \mathrm{~K})$. Maxima are generally reached at $35^{\circ}$, with a $5^{\circ}$ shift towards higher latitudes in the local summer. Previously detected TW3 latitude shifts (Pancheva et al., 2013) and the in situ DW1 evidence the same behavior. Maximum values occur in the equinoxes, coinciding with the expected maximum contribution from an overlapping DW1. Perturbations are significantly reduced over the Equator during January, as a TW3 effect would be (Pancheva et al., 2013).

At $120 \mathrm{~km}$, MIPAS $\left|n_{\text {odd }}-s\right|=0$ is negative between $50^{\circ} \mathrm{S}$ and $50^{\circ} \mathrm{N}$. These negative perturbations generally peak at the same altitude throughout the year, which implies that the local time phase also remains constant. The latitudinal structure could correspond to a second-order symmetric mode of DW1 and/or the first TW3 mode. Maximum pertur- bations occur during solstices around $20^{\circ} \mathrm{S}$ and $\mathrm{N}(-20 \mathrm{~K})$, in contrast to the mesosphere, where maximum amplitudes are found at the Equator during equinoxes.

At $140 \mathrm{~km}$, the positive peaks, following the subsolar point, move towards the local summer, when they present maximum amplitudes. The similarities of the $\left|n_{\text {odd }}-s\right|=0$ seasonal and latitudinal structure around $120 \mathrm{~km}$ with that at $140 \mathrm{~km}$ supports the possibility of downward propagation of the in situ thermospheric DW1. Additionally, MIPAS measurements show negative peaks at $140 \mathrm{~km}$ in autumn around $50^{\circ} \mathrm{N}$ and $50^{\circ} \mathrm{S}(10 \mathrm{~K})$. These could be associated with the positive perturbation at lower altitudes $(120 \mathrm{~km})$ for similar latitudes.

\subsection{The $\left|n_{\text {odd }}-s\right|=1$ mode}

The strongest tidal modes included in the MIPAS $\left|n_{\text {odd }}-s\right|=$ 1 longitudinal oscillation are DW2 and D0. TW2 oscilla- 

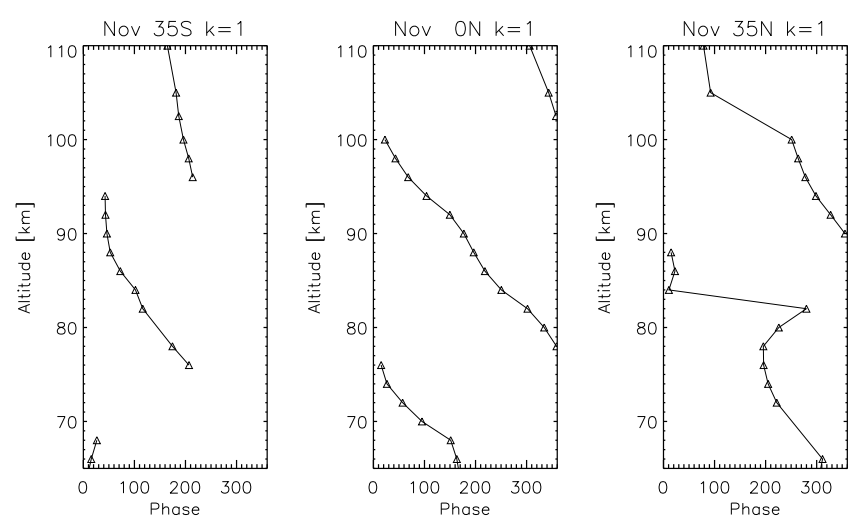

Figure 7. Phase of MIPAS average (2007-2012) $\left|n_{\text {odd }}-s\right|=1$ for November at $35^{\circ} \mathrm{S}$ (left), Equator (center) and $35^{\circ} \mathrm{N}$ (right).

tions are also embedded if present. The diurnal modes are the strongest among them. They may originate from a combination of DW1 interaction with SPW1 and the longitudinally varying tropospheric latent heat release related to the wave1 surface longitudinal asymmetry (Oberheide et al., 2005; Lieberman et al., 2015).

Figure 6 shows amplitudes and phases derived for November. Amplitudes maximize around the Equator, as well as $35^{\circ} \mathrm{N}$ and $35^{\circ} \mathrm{S}$, and peak at $85-90 \mathrm{~km}(4-15 \mathrm{~K})$. SH amplitudes are larger than in the $\mathrm{NH}$. The extratropical oscillations are out of phase with those at the Equator. The decreasing phase with altitude (right upper plot of Figs. 6 and 7) indicates a westward propagation if vertical propagation is assumed. This indicates a contribution from DW2. The vertical wavelength is $25 \mathrm{~km}$.

A hint of activity with smaller amplitudes $(2 \mathrm{~K}$ at $90 \mathrm{~km}$ and $6 \mathrm{~K} 105 \mathrm{~km}$ ) appears at $65^{\circ} \mathrm{S}$. These features are in phase and antiphase with the signals measured at the Equator and $35^{\circ}$, respectively, and also tilt westward with altitude. An analogous signature appears at $65^{\circ} \mathrm{N}$ but its propagation direction is not as coherent.

It is not evident from MIPAS data how efficiently this oscillation penetrates higher up in the thermosphere. At the very least, it does not increase with altitude in the 115$150 \mathrm{~km}$ range. This mode does not show a coherent structure and amplitudes usually oscillate around temperature error values at these altitudes.

Figure 6 also shows time series of the amplitudes and phases of MIPAS $\left|n_{\text {odd }}-s\right|=1$. Amplitudes at $68 \mathrm{~km}$ maximize in July, November and February (3-5 K). These maxima shift in latitude following the tropical local winter. This off-Equator displacement generally occurs at altitudes between 60 and $80 \mathrm{~km}$. It is also present in SABER measurements (Gan et al., 2014). Secondary maxima $(<2 \mathrm{~K})$ appear in July and November $20-30^{\circ}$ to the north and to the south of the primary maximum.

The wave amplitude at $86 \mathrm{~km}$ (typical $\left|n_{\text {odd }}-s\right|=1$ peaking altitude) peaks at the Equator during the equinoxes (10-
$15 \mathrm{~K}$ ) but also in July (8 K) (Fig. 6). These values are larger than the combination of those reconstructed from ISAMS for DW2 (4 K) and D0 (3 K) (Forbes and Wu, 2006) or from SABER DW2 (2 K) and D0 (4 K) (Zhang et al., 2006). The phase remains constant throughout the year except in July, when it shifts $180^{\circ}$. This reflects a change in the relative importance of the sources of the underlying tides, which is expected to be greater in July if tide-wave interaction dominates (see Fig. 3 in Oberheide et al., 2005).

The amplitude of $\left|n_{\text {odd }}-s\right|=1$ at $86 \mathrm{~km}$ reaches $4 \mathrm{~K}$ from September to December around $35^{\circ}$. It is latitudinally symmetric and out of phase with respect to the Equator. This value is in agreement with the combination of DW2 (2 K) and D0 $(2 \mathrm{~K})$ from SABER at a similar altitude in September 2004. The oscillation is also noticed at $35^{\circ} \mathrm{N}$ in July and $35^{\circ} \mathrm{S}$ in March $(4 \mathrm{~K})$.

The time series at $105 \mathrm{~km}$ is more structured. Maximum $\left|n_{\text {odd }}-s\right|=1$ amplitudes occur mostly around $30^{\circ}$ from November to March, particularly in the SH, and in July (larger in the $\mathrm{SH} ; 10 \mathrm{~K}$ ). The phase does not change significantly over the year and is latitudinally asymmetric. This is in contrast with behavior at lower altitudes, suggesting other HMEs or even-parity frequency tidal components as principal contributions. The oscillation at $105 \mathrm{~km}$ is significant at the Equator from October to December $(6-8 \mathrm{~K})$ and is out of phase with that at $30^{\circ} \mathrm{S}$.

These results are consistent with SABER measurements, showing D0 tide maxima at $110 \mathrm{~km}$ around $30-40^{\circ}$, particularly during the solstices and also strongest at $\mathrm{SH}$ local winter $(7 \mathrm{~K})$, and DW2 maxima at $100-105 \mathrm{~km}$ over the Equator, mainly from October to March (7 K) (Gan et al., 2014; Truskowski et al., 2014). SABER also showed contribution from DW2 at $35^{\circ} \mathrm{S}$ but not in the $\mathrm{NH}$, which could also be responsible for the hemispheric asymmetry here.

Maxima at $105 \mathrm{~km}$, out of phase with the ones at $35^{\circ} \mathrm{S}$, appear around $65^{\circ} \mathrm{N}$ and $\mathrm{S}(6-8 \mathrm{~K})$ only during NovemberDecember.

\subsection{The $\left|n_{\text {odd }}-s\right|=2$ mode}

MIPAS $\left|n_{\text {odd }}-s\right|=2$ longitudinal oscillation embeds the diurnal DE1 and DW3 and the terdiurnal TW1 components, of which DE1 is the strongest. These non-migrating tides most likely arise from nonlinear interactions between their migrating counterparts (DW1 and TW3) and $s=2$ stationary planetary waves (SPW2).

The detection of these tidal components has been reported seldom in the past. Indeed, this mode is weaker than those with $\left|n_{\text {odd }}-s\right|=0,1,4$ but it is a contribution with a coherent vertical propagation in MIPAS data above $90 \mathrm{~km}$ at certain latitudes (see below).

Figure 8 shows latitude-altitude maps of the derived amplitudes and phases for January and September. Both months show eastward-propagating oscillations above $90 \mathrm{~km}$ at $35^{\circ} \mathrm{S}$ $(2-5 \mathrm{~K})$ and $\mathrm{N}$ (3-8 K in January and $3 \mathrm{~K}$ in September). 

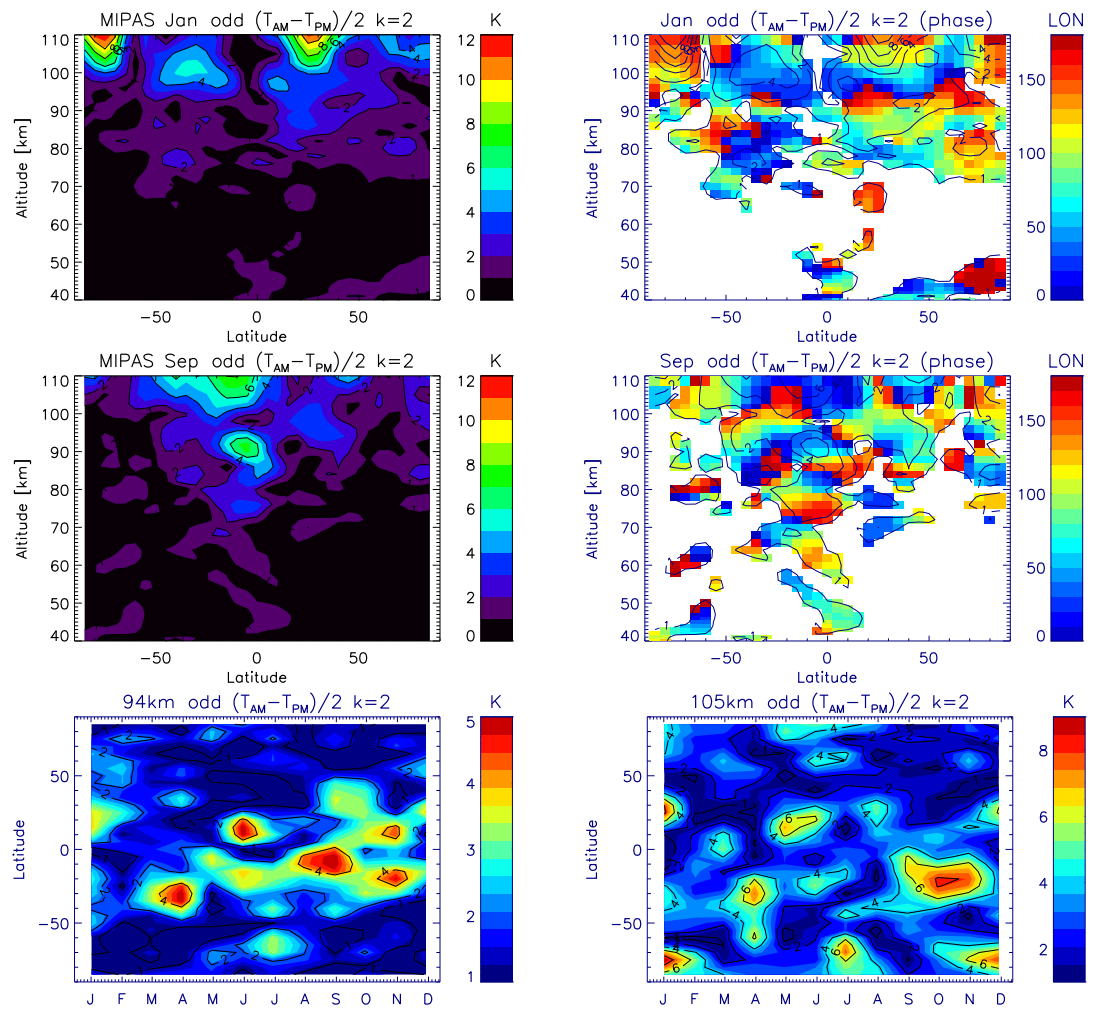

Figure 8. Latitude-altitude amplitude (left) and phase (right) fields for January (first row) and September (second row) and latitude-time horizontal slices of amplitudes (third row) at $94 \mathrm{~km}$ (left) and $105 \mathrm{~km}$ (right) of MIPAS average (2007-2012) $\left|n_{\text {odd }}-s\right|=2$ mode. Effects from DW3, DE1 and TW1 tidal modes are included.

September also exhibits a feature centered at $5-10^{\circ} \mathrm{S}$ above $75 \mathrm{~km}$ that mainly propagates westward and peaks at $90 \mathrm{~km}(6 \mathrm{~K})$. It is unclear whether the amplitudes measured around $110 \mathrm{~km}$ correspond uniquely to the same oscillation since there is no monotonic phase change with altitude. According to Truskowski et al. (2014), DW3 vertical wavelength prevents its penetration into the thermosphere if it originates in the troposphere. Therefore, the detection at these high altitudes with a lack of correspondence with an upward-propagating signal could be consistent with a local source or with the propagation of a tidal component different to DW3.

The wave spectrum derived from SABER in September around $110 \mathrm{~km}$ by Zhang et al. (2006) shows a contribution from DW3 at $10-20^{\circ} \mathrm{S}(6 \mathrm{~K})$ and $40-50^{\circ} \mathrm{S}(4 \mathrm{~K})$ and a small contribution from DE1 around $20^{\circ} \mathrm{N}(<4 \mathrm{~K})$. The direction of propagation of the waves derived here only coincide at $35^{\circ} \mathrm{S}$. However, CMAM DE1 simulations of Ward et al. (2005) showed a symmetric three-maxima latitudinal structure around $80-90 \mathrm{~km}$ dominating the mesopause (2 K) and converting into an asymmetric two-maxima structure in the lower thermosphere. Thus, MIPAS $\left|n_{\text {odd }}-s\right|=2$ structure probably responds to the overlapping of two significant contributions, in which DW3 dominates at extratropical latitudes and DE1 dominates at the Equator.
The time series of $\left|n_{\text {odd }}-s\right|=2$ at $94 \mathrm{~km}$ shows a large seasonal variability. The maximum at $5-10^{\circ} \mathrm{S}$ appears mainly in May and September with a varying amplitude (bottom left panel in Fig. 8). The oscillation is also noticeable in March-April and September around $30-40^{\circ} \mathrm{N}$ and S, when the mode is latitudinally asymmetric. July and November reveal a $4 \mathrm{~K}$ amplitude oscillation closer to the Equator $\left(20^{\circ}\right)$ that is latitudinally symmetric (in phase).

The time series at $105 \mathrm{~km}$ (bottom right panel of Fig. 8) shows an incoherent latitudinal pattern not clearly correlated to the one at $94 \mathrm{~km}$. This suggests the contribution of highorder Hough modes at higher altitudes, varying throughout the year. Whereas strong signatures for an antisymmetric Hough mode are found for January (4-6 K), April (2-4 K) and July $(2 \mathrm{~K})$, a symmetric mode is indicated for September.

\subsection{The $\left|n_{\text {odd }}-s\right|=3$ mode}

The combination of the DE2 and the DW4 tides produces a $\left|n_{\text {odd }}-s\right|=3$ longitudinal oscillation as seen by MIPAS. DE2 arises from the release of latent heat, and its latitudinal/seasonal pattern is associated with a modulation by the mean wind (Pancheva et al., 2010). Fixed local time wavenumber-3 structures are present in the ionosphere, but 

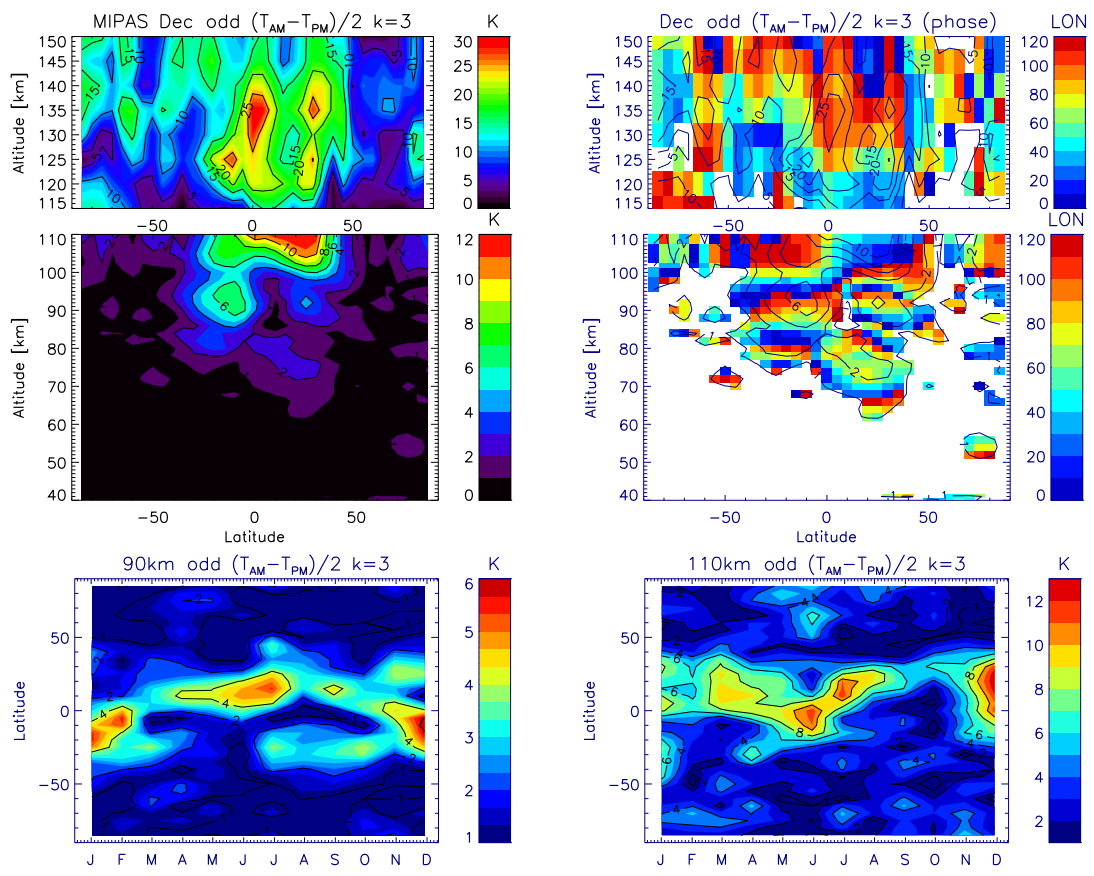

Figure 9. Latitude-altitude amplitude (left) and phase (right) fields for December MIPAS average (2007-2012) $\left|n_{\text {odd }}-s\right|=3$ longitudinal oscillations (first and second row) and average monthly mean time series of $\left|n_{\text {odd }}-s\right|=3$ amplitudes at $90 \mathrm{~km}$ (left) and $110 \mathrm{~km}$ (right). Contributions from DE2, DW4 and T0 tides are embedded.
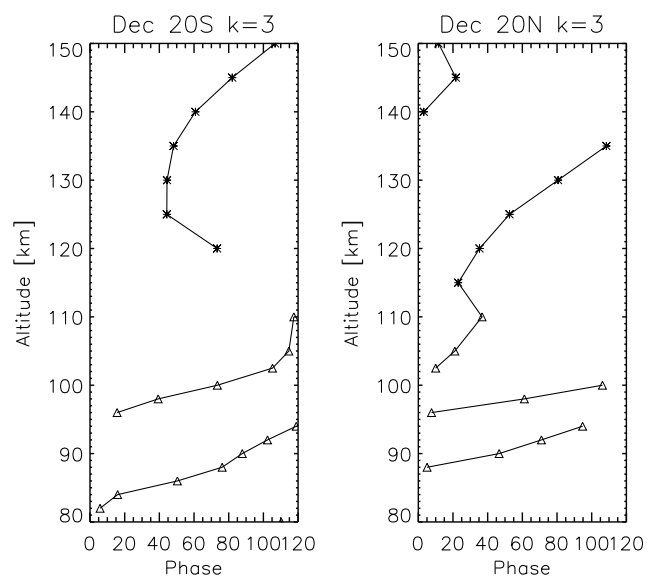

Figure 10. Phase of MIPAS average (2007-2012) $\left|n_{\text {odd }}-s\right|=3$ for December at $20^{\circ} \mathrm{S}$ (left) and $20^{\circ} \mathrm{N}$ (right).

DE2 forcing from below has not yet been clearly determined (Pedatella et al., 2008; England et al., 2009; Pancheva and Mukhtarov, 2010; Mukhtarov and Pancheva, 2011).

This is one of the dominating MIPAS zonal oscillations over the Equator around $110 \mathrm{~km}$ in December (12 K). Only the migrating component is stronger. This shows a latitudinally antisymmetric structure at $90 \mathrm{~km}$ during December (see Fig. 9). The amplitudes maximize at tropical latitudes and are larger in the SH. A symmetric mode dominates above
$100 \mathrm{~km}$ and amplitudes are significant at latitudes below 30$40^{\circ}$. Amplitudes increase up to $130-140 \mathrm{~km}(25 \mathrm{~K})$, where the oscillation starts dissipating. This pattern of enhanced activity during the $\mathrm{NH}$ winter agrees with previous studies for DE2 (Pedatella et al., 2008). MIPAS significant amplitudes in the $\mathrm{E}$ region are not reproduced in the CTMT and the GSWM DE2, which model $5 \mathrm{~K}$ maximum values above $110 \mathrm{~km}$.

The phase increases with altitude (right upper plots of Figs. 9 and 10). If upward propagation is assumed, this indicates contribution from an eastward-propagating wave. This indicates that, opposite to what Pancheva et al. (2010) state, DE2 may penetrate above $115 \mathrm{~km}$ but with a significantly longer vertical wavelength $(30 \mathrm{~km}$ at $140 \mathrm{~km}$ in contrast to $10-12 \mathrm{~km}$ in the upper mesosphere).

The change with altitude of the relative importance of the different Hough modes occurs throughout the year. This is deduced from the different latitudinal distribution of the amplitudes at 90 and at $110 \mathrm{~km}$ (bottom panels in Fig. 9). Amplitudes at $90 \mathrm{~km}$ peak during the solstices at around $20^{\circ}$ (4-6 K) and are larger in the local summer. The oscillation also peaks in the solstices at $110 \mathrm{~km}(12 \mathrm{~K})$ and exhibits an off-Equator displacement $\left(5-10^{\circ}\right)$ towards the local winter. These results agree with the DE2 seasonal behavior derived from SABER (Pancheva et al., 2010; Pancheva and Mukhtarov, 2011). 

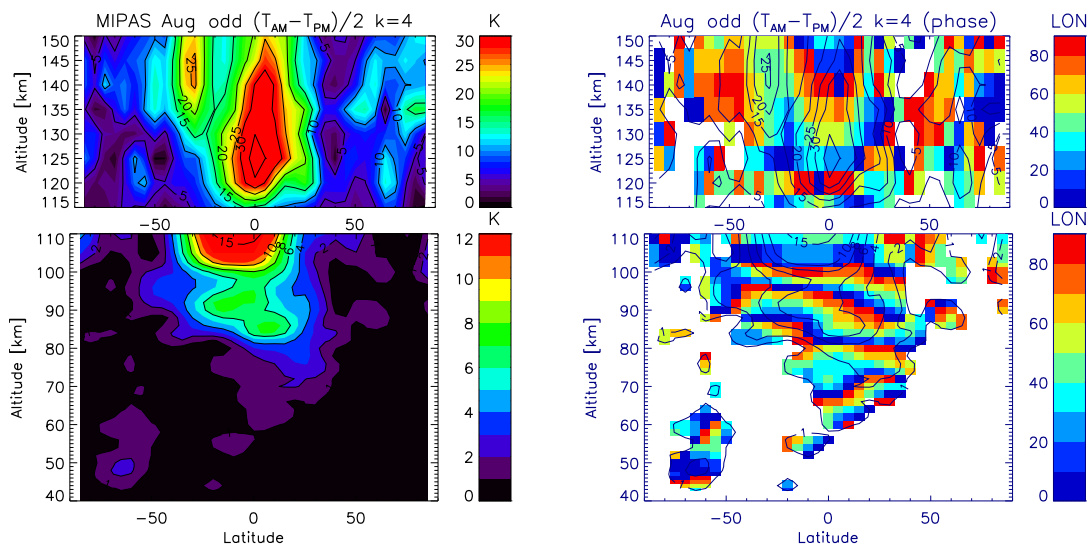

Figure 11. August average (2007-2012) monthly mean amplitudes (left) and phases (right) $\left|n_{\text {odd }}-s\right|=4$ oscillations from MIPAS $T_{\text {THER }}$ (115-150 km; upper panels) and $T_{\text {MLT }}(20-110 \mathrm{~km}$; bottom panels) temperatures. Note the different color scale. DE3, DW5 and TE1 tides are embedded.

\subsection{The $\left|n_{\text {odd }}-s\right|=4$ mode}

The $\left|n_{\text {odd }}-s\right|=4$ MIPAS longitudinal variation includes the diurnal non-migrating components DE3 and DW5. These tidal modes are thought to be excited by diurnally varying latent heat release over the wave-4 land-sea variation. $\left|n_{\text {odd }}-s\right|=4$ also contains the TE1 component. DE3 is the strongest non-migrating tidal effect in the lower thermosphere and has been widely studied. It is thought to be primarily responsible for the wave- 4 structure detected at higher altitudes in the thermosphere (Hagan et al., 2007), while the direct absorption of the incoming radiation might play a secondary role (Achatz et al., 2008). Quantification of the troposphere-originated DE3 is relevant for determining how much it contributes to the fixed local time zonal wavenumber-4 in the ionosphere (Oberheide et al., 2011a; Pedatella et al., 2012).

MIPAS $\left|n_{\text {odd }}-s\right|=4$ longitudinal oscillation has strong amplitudes in the lower thermosphere (at least below $135 \mathrm{~km}$ ) over the Equator. Figure 11 shows amplitudes and phases altitude-latitude cross section derived for August. The amplitudes are significant from the Equator to midlatitudes above $70 \mathrm{~km}$. They increase with altitude, reaching $8 \mathrm{~K}$ around $95 \mathrm{~km}, 10 \mathrm{~K}$ at $100 \mathrm{~km}$, and peak at $120-125 \mathrm{~km}$ $(35 \mathrm{~K})$. The mode starts dissipating at $125 \mathrm{~km}$ but maintains a consistent vertical propagation (increasing phase with altitude). The DE3 temperature amplitude maximum is located around $110-115 \mathrm{~km}$ in results from CTMT and the Whole Atmosphere Model (WAM) (Akmaev et al., 2008) and about $5 \mathrm{~km}$ below in GSWM-09. MIPAS peak is around $10 \mathrm{~km}$ above the altitude predicted by models. This result may impact on the modeling of the mechanisms controlling DE3 in the thermosphere. However, we note that the vertical resolution of MIPAS temperatures is approximately $10 \mathrm{~km}$ at these altitudes, enough to shift the peak and partially explain the difference. Interference with DW5 and/or TE1 is also possible.

The $\left|n_{\text {odd }}-s\right|=4$ phase decreases with latitude, so that the oscillations over the Equator and at $20-25^{\circ}$ are out of phase. The phase increases with altitude, pointing to DE3 as the main contributor if an upward propagation is assumed. The vertical wavelength in the mesosphere is $8-12 \mathrm{~km}$. The phase plot exhibits a crosswise structure, which decreases with height until the lower thermosphere, where the phase is almost latitudinally symmetric. This indicates the presence of an asymmetric HME below $95 \mathrm{~km}$ that is more efficiently dissipated as it propagates upwards than the symmetric ones. This confirms the results for the DE3 HMEs of the CTMT Oberheide and Forbes (2008a). In the lower thermosphere, the vertical wavelength increases to $20 \mathrm{~km}$.

Latitude-time slices at selected altitudes are plotted in Fig. 12. Maximum amplitudes occur around $10-20^{\circ} \mathrm{N}$ and $10-20^{\circ} \mathrm{S}$ at $84 \mathrm{~km}$, which are stronger in the $\mathrm{NH}$. The oscillation tilts to the north during the equinoxes and to the south at the beginning of the NH winter, and it is latitudinally extended and centered over the Equator during the $\mathrm{NH}$ summer, agreeing with the DE3 pattern from SABER (Gan et al., 2014; Zhang et al., 2006) and MLS (Forbes and Wu, 2006). The $4 \mathrm{~K}$ larger MIPAS amplitudes might be explained by contribution from DW5. Non-negligible amplitudes also appear in MIPAS data at high latitudes, at $60^{\circ}$ in July and at $80-85^{\circ}$ in November.

Large amplitudes mainly occur around the Equator at $94 \mathrm{~km}$, maximizing from June to September $(6-8 \mathrm{~K})$ (Fig. 12). These maximum values are $2 \mathrm{~K}$ larger than SABER DE3 (see, e.g., Gan et al., 2014). This seasonal pattern agrees with a cycle responding to the combined seasonal variation of the background atmosphere and of the diurnal heat source (Oberheide et al., 2006; Achatz et al., 2008). MIPAS also measures $5 \mathrm{~K}$ maxima close to the tropics in November- 

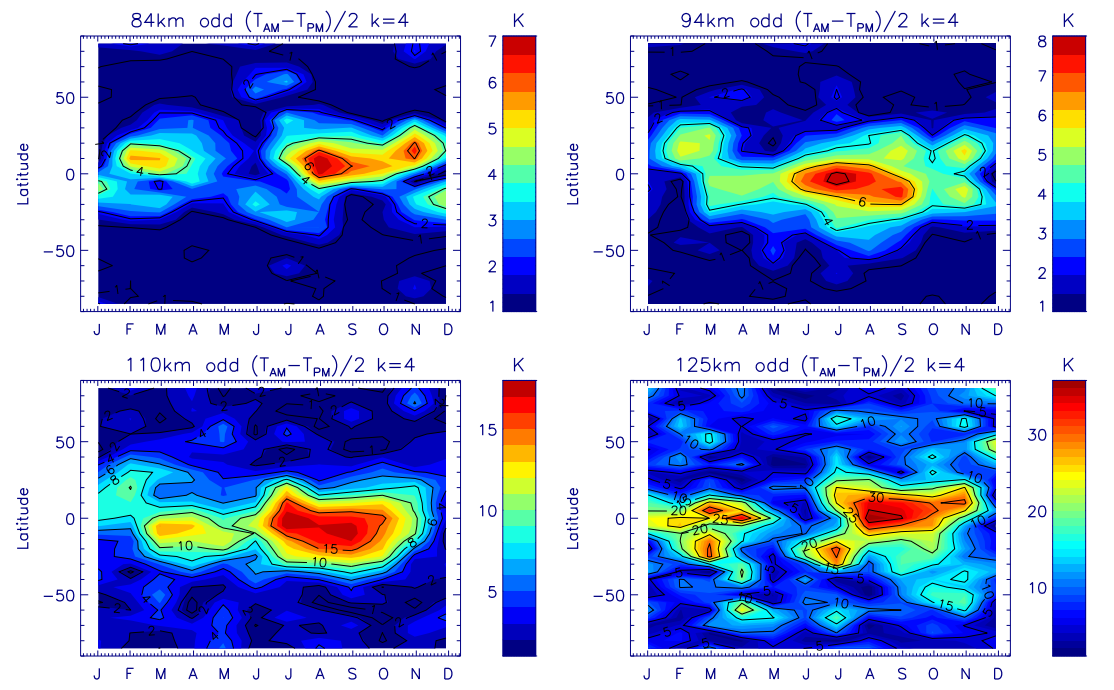

Figure 12. Time series of latitudinal distribution of average (2007-2012) monthly means amplitudes for the MIPAS $\left|n_{\text {odd }}-s\right|=4$ mode at 84, 94, 110 and $125 \mathrm{~km}$. DE3 and TE1 tidal oscillations are embedded.

December and February and high-latitude $\left(50-60^{\circ}\right)$ activity in July-August.

The oscillation is significantly amplified at $110 \mathrm{~km}(10-$ $15 \mathrm{~K})$ and $125 \mathrm{~km}(30 \mathrm{~K})$ but has a similar seasonal variability to that at lower altitudes (Fig. 12). MIPAS values at $110 \mathrm{~km}$ generally agree with those derived from SABER for DE3 at similar altitudes (Zhang et al., 2006; Gan et al., 2014), although they are larger $(2 \mathrm{~K})$ in March. DW5 contribution is also expected at these altitudes (a maximum of $4 \mathrm{~K}$, according to SABER).

This mode also presents hemispherically symmetric signatures at $50-60^{\circ}$ in July-August at $110 \mathrm{~km}(2-4 \mathrm{~K})$ and $125 \mathrm{~km}(10 \mathrm{~K})$ and in November at $80^{\circ}$ at $110 \mathrm{~km}(4 \mathrm{~K})$.

The phase at $110 \mathrm{~km}$ varies throughout the year over the Equator (not shown). It shifts towards the west with latitude or, in terms of local time phase and assuming a dominant eastward-propagating component (DE3), it occurs later in the day. The phase generally presents hemispherical symmetry.

The seasonal behavior reflects the seasonal change in the relative importance of the different Hough modes for most altitudes. There is a major contribution from a symmetric mode throughout the year at thermospheric altitudes, except from November to January. It is then overcome by $(95-110 \mathrm{~km})$ or competes with (around $125 \mathrm{~km}$ ) an antisymmetric mode, in agreement with HME from Oberheide and Forbes (2008a). July also presents a small contribution from the symmetric mode around $125 \mathrm{~km}$. However, it is then when the asymmetric mode is strongest, whereas Oberheide and Forbes (2008a) report it to be strongest only in January.

\section{Interannual variability}

Five years of continuous observations are insufficient to unambiguously link atmospheric processes through correlations but are adequate to check for tidal QBOs. Yearto-year variability in strengths of the measured longitudinal oscillations due to the effect of the zonal wind QBO is expected (McLandress, 2002; Mayr and Mengel, 2005; Xu et al., 2009; Huang et al., 2010). Oberheide et al. (2009) and references therein discuss the possible mechanisms through which the zonal wind QBO might affect daily temperature oscillations.

At each altitude and latitude, we have decomposed the amplitudes of MIPAS $\Delta T / 2$ derived $\left|n_{\text {odd }}-s\right|$ longitudinal oscillation modes from 2007 to 2012 into six intra-annual sinusoidal components (with 12-, 6-, 4-, 3-, 2.4- and 2-month periods), an interannual sinusoidal component (with its period as a free parameter) and a component proportional to the solar flux. We have allowed for solar cycle effects, for which we have accurate input energy variation, with the sole aim of deriving a more accurate interannual oscillation. Note that MIPAS time coverage spans from solar minimum to solar maximum, and thus all monotonic variations in temperature amplitudes, like trends, are embedded in this solar component. We have unambiguously found interannual variations consistent with a QBO in MIPAS data only for the strong $\left|n_{\text {odd }}-s\right|=0$ mode. A QBO effect in the DE3 component is not detected with confidence in MIPAS data. According to our Fig. 11, the 15-20\% DE3 amplitude variations during boreal summer reported by Oberheide et al. (2009) would imply QBO amplitudes of $0.5 \mathrm{~K}$ at $90 \mathrm{~km}$ and $1.5 \mathrm{~K}$ at $110 \mathrm{~km}$. These are within the limits of the corresponding MIPAS temperature errors at these altitudes. 

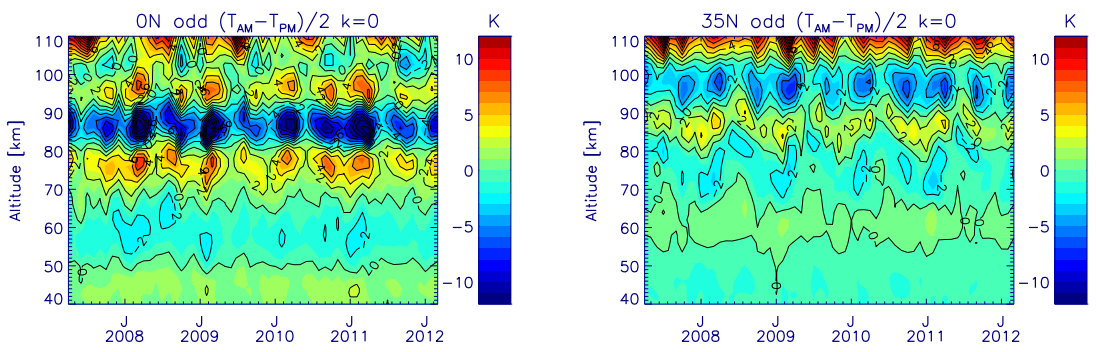

Figure 13. Time series of the MIPAS zonal mean of $\Delta T / 2$ monthly means ( $\left|n_{\text {odd }}-s\right|=0$ mode) at the Equator (left) and over $35^{\circ} \mathrm{N}$ (right).

Figure 13 shows the time series from 2007 to 2012 of MIPAS $\left|n_{\text {odd }}-s\right|=0$ amplitudes over the Equator and at $35^{\circ} \mathrm{N}$. We recall that these correspond to migrating tide total amplitudes only at the altitudes where the tidal phase or antiphase is 10:00, which are approximately located at the peaks in the vertical profiles. We have already mentioned in Sect. 3.1 that there is a seasonal variation in the altitudes of these peaks, particularly at extratropical latitudes. These altitudes vary during a calendar year by $2 \mathrm{~km}$ (up and down) around 78 and $85 \mathrm{~km}$ over the Equator, but this can be as much as $5 \mathrm{~km}$ around $75 \mathrm{~km}$ and $3 \mathrm{~km}$ at $88 \mathrm{~km}$ at $35^{\circ} \mathrm{N}$, being higher in the winter (Fig. 13). This also happens in the SH but to a significantly lesser extent (not shown). These changes in peak altitudes are most likely due to a change in phase. The vertical wavelength barely changes because the peak altitude shift occurs at most altitudes simultaneously.

This behavior is repeated annually, pointing to a persistent seasonal effect. It could arise from a seasonal change in the relative contribution from the different sources of this component, namely the semiannually varying background atmosphere and the symmetry of the heating source. Due to the hemispherical asymmetry, we attribute this behavior to the annual oscillation of the background atmosphere, significantly larger in the $\mathrm{NH}$. Interaction with other dynamical features during the winter are not ruled out.

A QBO in MIPAS $\left|n_{\text {odd }}-s\right|=0$ mode amplitudes is noticeable in Fig. 13, particularly at the Equator. Figure 14 shows these time series at 44,76 and $86 \mathrm{~km}$ over the Equator (approximate peaking altitudes in the equinoxes) and the fitted annual, semiannual and interannual components. Note that we kept the sign of the perturbations. The interannual component (red) competes with the combination of the semiannual and the annual oscillations (grey) below $80 \mathrm{~km}$. We also show two different representations of the zonal wind stratospheric QBO (SQBO) in Fig. 14: that obtained at the NOAA-ESRL Physical Sciences Division from the zonal average of the $30 \mathrm{mb}$ zonal wind at the Equator calculated from the NCEP/NCAR Reanalysis (http://www.esrl.noaa.gov/psd/) and that measured at $30 \mathrm{mb}$ from a radiosonde station in Singapore, compiled by the Freie Universität Berlin (http://www.geo.fu-berlin.de/ en/met/ag/strat/produkte/qbo/index.html). The phase of the background zonal wind SQBO at $30 \mathrm{mb}$ is opposite to that of
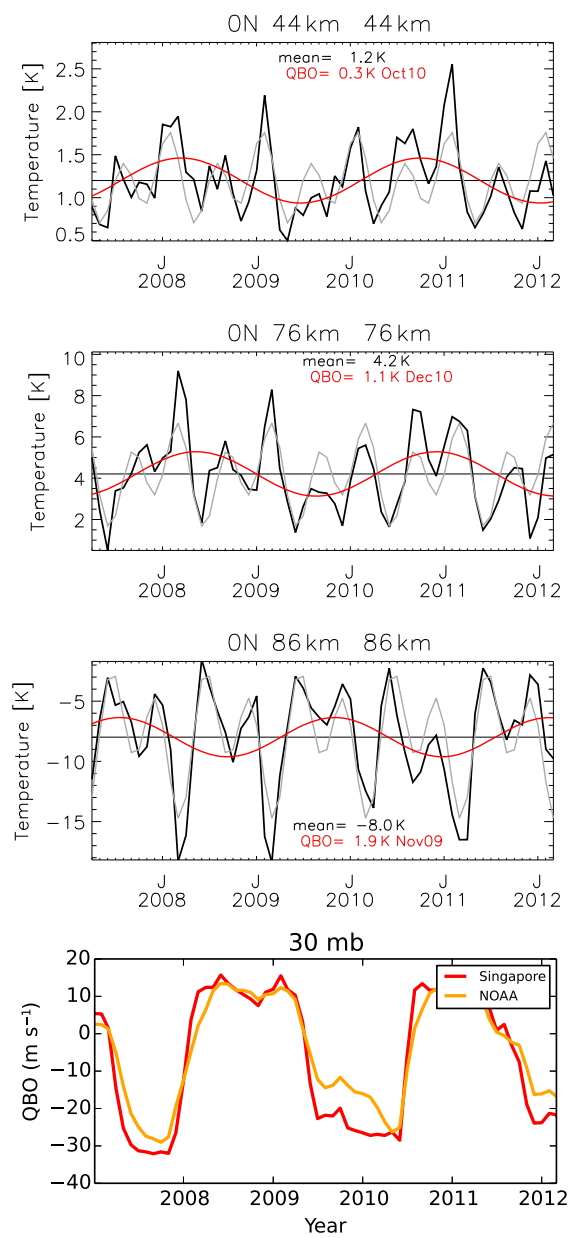

Figure 14. MIPAS monthly mean $\left|n_{\text {odd }}-s\right|=0$ mode perturbations (black lines) at 44,76 and $86 \mathrm{~km}$ and their decomposition in annual plus semiannual components (grey) and QBO (red). Singapore winds at $30 \mathrm{mb}$ are also plotted in the bottom panel for reference.

the mesospheric QBO (MQBO) (Burrage et al., 1996) - that is, when the SQBO is in its westerly phase, the MQBO is in its easterly phase.

The period of the derived interannual component (red) of MIPAS $\left|n_{\text {odd }}-s\right|=0$ agrees with that of the Singapore winds at all altitudes (see Fig. 14). The (absolute value) of 


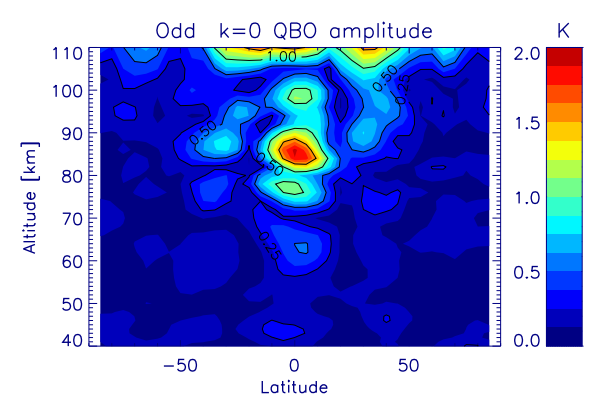

Figure 15. QBO amplitudes derived from the MIPAS $\left|n_{\text {odd }}-s\right|=0$ longitudinal mode extracted from monthly means from April 2007 to March 2012.

this interannual component is in phase with the zonal wind SQBO. In other words, MIPAS $\left|n_{\text {odd }}-s\right|=0$ strengthens at all altitudes simultaneously during the SQBO westerly phase, in agreement with previous observational studies (Xu et al., 2009; Wu et al., 2011), and therefore the MQBO easterly phase. Ekanayake et al. (1997) found that longitudinally propagating tides are stronger for mean zonal winds blowing in the opposite direction, which implies that a westwardpropagating tide, like DW1, should be stronger for westerlies. In combination, these facts suggest that the QBO effect on mesospheric migrating tides is mainly not produced locally by the zonal wind MQBO. A more likely possibility is a zonal wind QBO interaction with tides in the stratosphere. This supports the argument by Forbes and Vincent (1989) of varying stratospheric tide filtering during upward propagation caused by the varying mean zonal winds instead of a local effect in the mesosphere, where dissipation starts, as Oberheide et al. (2009) suggested as more plausible for DE3. Note that interannual variation at tropospheric altitudes, where the tide mainly originates, cannot be ruled out.

A QBO is also present everywhere else where MIPAS $\left|n_{\text {odd }}-s\right|=0$ mode is significant: there are stronger migrating tides during the SQBO eastward phase. Figure 15 shows a map of the QBO amplitude. Values are smaller than $0.5 \mathrm{~K}$ below $75 \mathrm{~km}$ over the Equator and below $105 \mathrm{~km}$ around $30^{\circ} \mathrm{N}$ and $30^{\circ} \mathrm{S}, 1 \mathrm{~K}$ at $76 \mathrm{~km}, 2 \mathrm{~K}$ at $86 \mathrm{~km}, 1 \mathrm{~K}$ at $98 \mathrm{~km}$ and $1.5 \mathrm{~K}$ at $110 \mathrm{~km}$. These results agree with those derived from SABER below $90 \mathrm{~km}$ (Xu et al., 2009). Above, SABER values are about $1 \mathrm{~K}$ larger.

\section{Summary}

The Sun-synchronous Michelson Interferometer for Passive Atmospheric Sounding (MIPAS) globally sounded the atmospheric limb from the stratosphere to the lower thermosphere. MIPAS took measurements at two fixed local times during its ascending (10:00) and descending (22:00) nodes. Subtraction of the descending and ascending node measurement pairs,
$\Delta T / 2$, at each latitude, altitude and longitude eliminates the background atmosphere, the daily-invariant longitudinal oscillations (like planetary waves) and also the longitudinal oscillations with daily frequencies such that they are an even integer factor of the $24 \mathrm{~h}$ day (like semidiurnal tides). Thus, the zonal variation of the $\Delta T / 2$ depicts a "solar view" mainly of the diurnal and terdiurnal tidal components.

Extraction of the underlying longitudinal oscillations by spectral analysis isolates the amplitudes and phases of the contributing MIPAS zonal wavenumbers $k$. Each wavenumber $k$ comprises the combined contribution of the tidal modes such that their daily frequency $n$, an odd integer, and their zonal wavenumber $s$ are $\left|n_{\text {odd }}-s\right|=k$. The tidal modes embedded in MIPAS $k$ modes are listed in Table 1.

MIPAS spectra covered the $\mathrm{CO}_{2} 15 \mu \mathrm{m}$ and NO $5.3 \mu \mathrm{m}$ emissions from which temperatures from 40 to $150 \mathrm{~km}$ are derived. We extracted the wavenumber $k=0-4$ longitudinal waves from these temperatures globally from April 2007 to March 2012 and have made them available to the scientific community. To our knowledge, this is the first time zonal oscillations in temperature are derived in this altitude range globally from a single instrument.

We analyze and characterize the behavior of MIPAS $\left|n_{\text {odd }}-s\right|$ longitudinal oscillations from a climatological point of view from averages of monthly mean MIPAS $\Delta T / 2$. The results generally agree well with measurements from other instruments, like SABER or MLS. They reveal the following:

- Migrating tidal perturbations with odd $n$ below $105 \mathrm{~km}$ are stronger during the equinoxes. They are latitudinally symmetric in strength. Their phases exhibit a seasonal variation, with a delay in the winter months that is larger in the NH. The dominating tidal mode at latitudes below $50^{\circ}$, probably the first mode of the upward-propagated DW1, rapidly dissipates above $105 \mathrm{~km}$.

- At $110 \mathrm{~km}$, the combination of the diurnal and terdiurnal migrating tide contributions produces maxima around $35^{\circ} \mathrm{N}$ and $35^{\circ} \mathrm{S}$ from September to May and from $35^{\circ} \mathrm{N}$ to $35^{\circ} \mathrm{S}$ from June to August. They shift $5^{\circ}$ to higher latitudes in the local summer. TW3 might also be responsible for the strong migrating perturbations measured at $120 \mathrm{~km}$ but contributions from an upward-propagated DW1 high-order mode or from the in situ-generated thermospheric tide are also a possibility.

- The thermospheric DW1 above $130 \mathrm{~km}$ produces maximum perturbations off the Equator, tracking the subsolar point and peaking in the local summer.

- MIPAS measured impact from migrating tides with $n_{\text {odd }}$ at southern high-latitude summer, with alternating maxima and minima at 90 and $100 \mathrm{~km}$ in phase with those at $35^{\circ}$. This agrees with previous ground-based detections (Lübken et al., 2011). MIPAS additionally detected a weaker counterpart in the NH summer. 
- Besides equatorial activity, $\left|n_{\text {odd }}-s\right|=1$ also exhibits extratropical $\left(35^{\circ}\right)$ and high-latitude $\left(65^{\circ}\right)$ activity in the MLT, particularly in the SH from November to January.

- $\left|n_{\text {odd }}-s\right|=2$ presents significant seasonal variability with a latitudinal structure responding to the overlap of two contributions, a westward-propagating oscillation that dominates at extratropical latitudes and an eastward-propagating one that dominates at the Equator.

- $\left|n_{\text {odd }}-s\right|=3$ is the strongest non-migrating mode in December and is also noticeable in November and January. A wave tilting eastward with altitude and which is already detected at $70 \mathrm{~km}$ penetrates well into the lower thermosphere, with a significantly larger vertical wavelength than in the mesosphere.

- MIPAS shows a prominent wavenumber-4 structure starting at $70 \mathrm{~km}$ and peaking around $135 \mathrm{~km}(15 \mathrm{~km}$ above results from models). The latitudinal distribution reveals a contribution from a symmetric Hough mode in the lower thermosphere, which propagates upwards more easily than the antisymmetric one dominating in the mesosphere.

- $\left|n_{\text {odd }}-s\right|=4$ expands to higher latitudes in JulyAugust, when hemispherically symmetric footprints are detected at $50-60^{\circ}$ above $85 \mathrm{~km}$. Signatures of this mode are also detected in November at $80^{\circ}$.
We also studied the interannual variability in the amplitudes of the MIPAS $\left|n_{\text {odd }}-s\right|$ wavenumbers derived from monthly mean MIPAS $\Delta T / 2$. We unambiguously detect a $\left|n_{\text {odd }}-s\right|=0$ QBO, reaching $2 \mathrm{~K}$ in the upper mesosphere at low latitudes. Comparison of tidal and zonal wind stratospheric and mesospheric QBO phases suggests that the QBO effect on tides does not mainly occur in the mesosphere.

The good MIPAS temporal resolution and global coverage observations extending from the stratosphere to the lower thermosphere presented here are useful for testing general circulation models considering tidal effects in the MLT region and may well present a challenge for them to model their vertical, latitudinal and temporal dependence. A thorough analysis of particular cases found here is needed and will be the focus of future work.

\section{Data availability}

The MIPAS datasets used in this paper can be accessed at https://www.imk-asf.kit.edu/english/308.php. 


\section{Appendix A: Methodology for extraction of odd-parity daily frequency tidal components}

Considering the effect of tides as the only source of longitudinal variability, an atmospheric variable $X$ (like temperature or species concentration) measured at longitude $\lambda$, altitude $z$, latitude $\phi$ and local solar time $t$ can be described as the variable zonal mean $\bar{X}$ at $z$ and $\phi$ perturbed by the sum of the tidal oscillations $X_{n, s}^{\prime}$, with zonal wavenumber $s$ and daily wave frequency $n$, at position $(\lambda, z, \phi)$ and time $t$ :

$X(\lambda, t)=\bar{X}+\sum_{n, s} X_{n, s}^{\prime}(\lambda, t)$,

where, for clarity, the dependence of $X, \bar{X}$ and $X_{n, s}^{\prime}$ on $z$ and $\phi$ is not written. The tidal oscillations can be expressed as sinusoidal longitudinal oscillations of the form (e.g., Williams and Avery, 1996)

$X_{n, s}^{\prime}(\lambda, t)=A_{n, s} \cos \left(n \Omega t-(n-s) \lambda+\Phi_{n, s}\right)$,

where $\Omega=2 \pi / 24$ is the Earth's angular velocity, and the oscillation amplitude $A_{n, s}$ and phase $\Phi_{n, s}$ are functions of $z$ and $\phi$. Note that this expression can be easily expressed in terms of universal time $t^{\prime}$ using $t=t^{\prime}+\frac{24}{2 \pi} \lambda$. The zonal wavenumber $s$ is an integer number defined such that $s<$ 0 refers to eastward-propagating tides, $s>0$ to westwardpropagating tides and $s=0$ to stationary tides. The daily wave frequency $n$ is a positive integer such that $n=1$ for a diurnal component, $n=2$ for a semidiurnal component, and so on.

For the particular case of Sun-synchronous instrument observations, the local solar times of the ascending and descending segments, $t_{\mathrm{a}}$ and $t_{\mathrm{d}}$, are fixed and fulfill $t_{\mathrm{a}}=t_{\mathrm{d}}+12$. A tidal perturbation at local time $t_{\mathrm{a}}, X_{n, s}^{\prime}\left(\lambda, t_{\mathrm{a}}\right)$, is then related to that at $t_{\mathrm{d}}, X_{n, s}^{\prime}\left(\lambda, t_{\mathrm{d}}\right)$, through

$$
\begin{aligned}
X_{n, s}^{\prime}\left(\lambda, t_{\mathrm{a}}\right) & =A_{n, s} \cos \left(n \Omega t_{\mathrm{a}}-(n-s) \lambda+\Phi_{n, s}\right) \\
& =A_{n, s} \cos \left(n \Omega t_{\mathrm{d}}+n \pi-(n-s) \lambda+\Phi_{n, s}\right) \\
& =(-1)^{n} X_{n, s}^{\prime}\left(\lambda, t_{\mathrm{d}}\right) .
\end{aligned}
$$

Therefore, half the difference of the variable observed at longitude $\lambda$ at the descending node local time $X\left(\lambda, t_{\mathrm{d}}\right)$ and at the ascending node local time $X\left(\lambda, t_{\mathrm{a}}\right)$ is

$$
\begin{aligned}
\Delta X / 2 & =\frac{X\left(\lambda, t_{\mathrm{d}}\right)-X\left(\lambda, t_{\mathrm{a}}\right)}{2} \\
& =\frac{1}{2}\left[\sum_{n, s} X_{n, s}^{\prime}\left(\lambda, t_{\mathrm{d}}\right)-\sum_{n, s}(-1)^{n} X_{n, s}^{\prime}\left(\lambda, t_{\mathrm{d}}\right)\right] \\
& =\sum_{n_{\mathrm{odd}}} \sum_{s} X_{n, s}^{\prime}\left(\lambda, t_{\mathrm{d}}\right),
\end{aligned}
$$

where addends with even $n$ and $n=0$ (stationary longitudinal oscillations) cancel out.
Defining $k=|n-s|$, with $k \in \mathbb{N}, \Delta X / 2$ in Eq. (A4) can be written as

$$
\begin{aligned}
\Delta X / 2 & =\sum_{n_{\text {odd }}} X_{n, n}^{\prime}\left(t_{\mathrm{d}}\right)+\sum_{n_{\text {odd }}, s<n} X_{n, s}^{\prime}\left(\lambda, t_{\mathrm{d}}\right) \\
& +\sum_{n_{\text {odd }}, s>n} X_{n, s}^{\prime}\left(\lambda, t_{\mathrm{d}}\right)=\sum_{n_{\text {odd }}} X_{n, n}^{\prime}\left(t_{\mathrm{d}}\right) \\
& +\sum_{k} \sum_{n_{\text {odd }}} X_{n, n-k}^{\prime}\left(\lambda, t_{\mathrm{d}}\right)+X_{n, n+k}^{\prime}\left(\lambda, t_{\mathrm{d}}\right) .
\end{aligned}
$$

Since $t_{\mathrm{d}}$ is fixed, $\Delta X / 2$ is a function of longitude that can be Fourier-decomposed at each $z$ and $\phi, \Delta X / 2=C_{0}+$ $\sum_{k} C_{k} \cos \left(k\left(\lambda-\theta_{k}\right)\right)$. By making a term-to-term correspondence of this harmonic decomposition with the right-hand side of Eq. (A5) and using Eq. (A2), each $k$-order Fourier term becomes equal to

$$
\begin{gathered}
C_{k} \cos \left(k\left(\lambda-\theta_{k}\right)\right)=\sum_{n_{\text {odd }}} X_{n, n-k}^{\prime}\left(\lambda, t_{\mathrm{d}}\right)+X_{n, n+k}^{\prime}\left(\lambda, t_{\mathrm{d}}\right) \\
=\sum_{n_{\text {odd }}} A_{n, n \pm k} \cos \left(n \Omega t_{\mathrm{d}} \pm k \lambda+\Phi_{n, n \pm k}\right) .
\end{gathered}
$$

$k$ 's are apparent longitudinal wavenumbers of the $\Delta X / 2 \mathrm{de}$ composition. Modes that fulfill the requirement that $n$ is odd and $s=n \pm k$ appear to have a $k$ wavenumber on the Sunsynchronous instrument $\Delta X / 2$ and, thus, combine and are embedded in the $k=|n-s|$ term. We hereafter denote this combined oscillation as $\left|n_{\text {odd }}-s\right|=k$. The major tidal components contributing to each apparent zonal wavenumber $k$ are listed in Table 1.

Even if the tidal modes with the same $n$ parity and the same $|n-s|$ are aliased, a close look at the derived phases $\theta_{k}$ and their dependence with altitude ultimately helps discern the dominance of a certain direction of horizontal propagation.

The zero-order Fourier term is equal to

$$
C_{0}=\sum_{n_{\text {odd }}} X_{n, n}^{\prime}\left(t_{\mathrm{d}}\right)=\sum_{n_{\text {odd }}} A_{n} \cos \left(n \Omega t_{\mathrm{d}}+\Phi_{n, n}\right),
$$

i.e., the addition of the solar migrating components $(s=n)$, which do not depend on $\lambda$ but only on local time $t_{\mathrm{d}}$. This equation shows that, even if only one mode dominates, the derived amplitude $C_{0}$ only corresponds to the amplitude of the tidal component $A_{n, n}$ at the altitudes where the phase $\Phi_{n, n}$ is $n \Omega t_{\mathrm{d}}$ or $n \Omega t_{\mathrm{a}}$. These altitudes show up as maxima (or minima) in the derived $C_{0}$ vertical profile. Another piece of information comes from the vertical nodes of that profile, corresponding to altitudes for which the phase is $n \Omega\left(t_{\mathrm{d}} \pm 6\right)$.

A method similar to the one described here was successfully applied to CRISTA data initially by Oberheide et al. (2002) and recently to SABER and MLS data by Lieberman et al. (2015). Li et al. (2015) also present an analogous analysis but applied to any two fixed local times for the descending and the ascending nodes. In the later case, the isolation of individual tidal components is then possible if only two daily frequencies $n$ contribute. 
Analogously to the subtraction, the sum of the variable pairs measured at the descending and at the ascending node LSTs at longitude $\lambda$ allows for the determination of the $n_{\text {even }}$ modes. 
Acknowledgements. Maya García-Comas was financially supported by MINECO through its "Ramon y Cajal" subprogram. The IAA team was supported by the Spanish MINECO, through project ESP2014-54362-P, and EC FEDER funds. IMK/IAA-generated MIPAS data can be accessed by request at https://www.imk-asf.kit.edu/english/1500.php.

Edited by: F.-J. Lübken

Reviewed by: three anonymous referees

\section{References}

Achatz, U., Grieger, N., and Schmidt, H.: Mechanisms controlling the diurnal solar tide: Analysis using a GCM and a linear model, J. Geophys. Res., 113, A08303, doi:10.1029/2007JA012967, 2008.

Akmaev, R. A., Fuller-Rowell, T. J., Wu, F., Forbes, J. M., Zhang, X., Anghel, A. F., Iredell, M. D., Moorthi, S., and Juang, H.-M.: Tidal variability in the lower thermosphere: Comparison of Whole Atmosphere Model (WAM) simulations with observations from TIMED, Geophys. Res. Lett., 35, L03810, doi:10.1029/2007GL032584, 2008.

Beig, G., Keckhut, P., Lowe, R. P., Roble, R. G., Mlynczak, M. G., Scheer, J., Fomichev, V. I., Offermann, D., French, W. J. R., Shepherd, M. G., Semenov, A. I., Remsberg, E. E., She, C. Y., Lübken, F. J., Bremer, J., Clemesha, B. R., Stegman, J., Sigernes, F., and Fadnavis, S.: Review of mesosopheric temperature trends, Rev. Geophys., 41, 1015, doi:10.1029/2002RG000121, 2003.

Bermejo-Pantaleón, D., Funke, B., López-Puertas, M., GarcíaComas, M., Stiller, G. P., von Clarmann, T., Linden, A., Grabowski, U., Höpfner, M., Kiefer, M., Glatthor, N., Kellmann, S., and Lu, G.: Global Observations of Thermospheric Temperature and Nitric Oxide from MIPAS spectra at $5.3 \mu \mathrm{m}$, J. Geophys. Res., 116, A10313, doi:10.1029/2011JA016752, 2011.

Bruinsma, S. L. and Forbes, J. M.: Anomalous behavior of the thermosphere during solar minimum observed by CHAMP and GRACE, J. Geophys. Res.-Space, 115, A11323, doi:10.1029/2010JA015605, 2010.

Burrage, M. D., Vincent, R. A., Mayr, H. G., Skinner, W. R., Arnold, N. F., and Hays, P. B.: Long-term variability in the equatorial middle atmosphere zonal wind, J. Geophys. Res., 101, 12847, doi:10.1029/96JD00575, 1996.

Chapman, S. and Lindzen, R. S.: Atmospheric Tides, Reidel, Dordrecht, the Netherlands, 1970.

Cho, Y.-M. and Shepherd, G.: Resolving daily wave 4 nonmigrating tidal winds at equatorial and midlatitudes with WINDII: DE3 and SE2, J. Geophys. Res.-Space, 120, 10053-10068, doi:10.1002/2015JA021903, 2015.

Chu, Y.-H., Wu, K.-H., and Su, C.-L.: A new aspect of ionospheric E region electron density morphology, J. Geophys. Res.-Space, 114, A12314, doi:10.1029/2008JA014022, 2009.

Davis, R. N., Du, J., Smith, A. K., Ward, W. E., and Mitchell, N. J.: The diurnal and semidiurnal tides over Ascension Island $\left(8^{\circ} \mathrm{S}\right.$, $\left.14^{\circ} \mathrm{W}\right)$ and their interaction with the stratospheric quasi-biennial oscillation: studies with meteor radar, eCMAM and WACCM, Atmos. Chem. Phys., 13, 9543-9564, doi:10.5194/acp-13-95432013, 2013.
Du, J. and Ward, W. E.: Terdiurnal tide in the extended Canadian Middle Atmospheric Model (CMAM), J. Geophys. Res.-Atmos., 115, D24106, doi:10.1029/2010JD014479, 2010.

Eckermann, S. D. and Marks, C. J.: An idealized ray model of gravity wave-tidal interactions, J. Geophys. Res., 101, 21195, doi:10.1029/96JD01660, 1996.

Ekanayake, E. M. P., Aso, T., and Miyahara, S.: Background wind effect on propagation of nonmigrating diurnal tides in the middle atmosphere, J. Atmos. Sol.-Terr. Phy., 59, 401-429, doi:10.1016/S1364-6826(96)00012-0, 1997.

England, S. L., Maus, S., Immel, T. J., and Mende, S. B.: Longitudinal variation of the E-region electric fields caused by atmospheric tides, Geophys. Res. Lett., 33, L21105, doi:10.1029/2006GL027465, 2006.

England, S. L., Zhang, X., Immel, T. J., Forbes, J. M., and DeMajistre, R.: The effect of non-migrating tides on the morphology of the equatorial ionospheric anomaly: seasonal variability, Earth Planet. Space, 61, 493-503, doi:10.1186/BF03353166, 2009.

Fischer, H., Birk, M., Blom, C., Carli, B., Carlotti, M., von Clarmann, T., Delbouille, L., Dudhia, A., Ehhalt, D., Endemann, M., Flaud, J. M., Gessner, R., Kleinert, A., Koopman, R., Langen, J., López-Puertas, M., Mosner, P., Nett, H., Oelhaf, H., Perron, G., Remedios, J., Ridolfi, M., Stiller, G., and Zander, R.: MIPAS: an instrument for atmospheric and climate research, Atmos. Chem. Phys., 8, 2151-2188, doi:10.5194/acp-8-2151-2008, 2008.

Forbes, J. M. and Garrett, H. B.: Solar diurnal tide in the thermosphere, J. Atmos. Sci., 33, 2226-2241, doi:10.1175/15200469(1976)033<2226:SDTITT>2.0.CO;2, 1976.

Forbes, J. M. and Garrett, H. B.: Theoretical studies of atmospheric tides, Rev. Geophys. Space Phys., 17, 1951-1981, doi:10.1029/RG017i008p01951, 1979.

Forbes, J. M. and Hagan, M. E.: Thermospheric extensions of the classical expansion functions for semidiurnal tides, J. Geophys. Res., 87, 5253-5259, doi:10.1029/JA087iA07p05253, 1982.

Forbes, J. M. and Vincent, R. A.: Effects of mean winds and dissipation on the diurnal propagating tide - An analytic approach, Planet. Space Sci., 37, 197-209, doi:10.1016/00320633(89)90007-X, 1989.

Forbes, J. M. and Wu, D.: Solar tides as revealed by measurements of mesosphere temperature by the MLS experiment on UARS, J. Atmos. Sci., 63, 1776-1797, 2006.

Forbes, J. M., Zhang, X., and Hagan, M. E.: Simulations of diurnal tides due to tropospheric heating from the NCEP/NCAR Reanalysis Project, Geophys. Res. Lett., 28, 3851-3854, doi:10.1029/2001GL013500, 2001.

Forbes, J. M., Zhang, X., Palo, S., Russell, J., Mertens, C. J., and Mlynczak, M.: Tidal variability in the ionospheric dynamo region, J. Geophys. Res., 113, A02310, doi:10.1029/2007JA012737, 2008.

Forbes, J. M., Bruinsma, S. L., Zhang, X., and Oberheide, J.: Surface-exosphere coupling due to thermal tides, Geophys. Res. Lett., 36, L15812, doi:10.1029/2009GL038748, 2009.

Forbes, J. M., Zhang, X., and Bruinsma, S. L.: New perspectives on thermosphere tides: 2. Penetration to the upper thermosphere, Earth Planet. Space, 66, 122, doi:10.1186/1880-5981-66-122, 2014.

Fritts, D. C. and Vincent, R. A.: Mesospheric momentum flux studies at Adelaide, Australia - Observations and a gravity wave-tidal interaction model, J. Atmos. Sci., 44, 605-619, 
doi:10.1175/1520-0469(1987)044<0605:MMFSAA>2.0.CO;2, 1987.

Funke, B., López-Puertas, M., García-Comas, M., Kaufmann, M., Höpfner, M., and Stiller, G. P.: GRANADA: a Generic RAdiative traNsfer AnD non-LTE population Algorithm, J. Quant. Spectrosc. Ra., 113, 1771-1817, doi:10.1016/j.jqsrt.2012.05.001, 2012.

Gan, Q., Du, J., Ward, W. E., Beagley, S. R., Fomichev, V. I., and Zhang, S.: Climatology of the diurnal tides from eCMAM30 (1979 to 2010) and its comparison with SABER, Earth Planet. Space, 66, 103, doi:10.1186/1880-5981-66-103, 2014.

García-Comas, M., Funke, B., López-Puertas, M., BermejoPantaleón, D., Glatthor, N., von Clarmann, T., Stiller, G., Grabowski, U., Boone, C. D., French, W. J. R., Leblanc, T., López-González, M. J., and Schwartz, M. J.: On the quality of MIPAS kinetic temperature in the middle atmosphere, Atmos. Chem. Phys., 12, 6009-6039, doi:10.5194/acp-12-6009-2012, 2012.

García-Comas, M., Funke, B., Gardini, A., López-Puertas, M., Jurado-Navarro, A., von Clarmann, T., Stiller, G., Kiefer, M., Boone, C. D., Leblanc, T., Marshall, B. T., Schwartz, M. J., and Sheese, P. E.: MIPAS temperature from the stratosphere to the lower thermosphere: Comparison of vM21 with ACE-FTS, MLS, OSIRIS, SABER, SOFIE and lidar measurements, Atmos. Meas. Tech., 7, 3633-3651, doi:10.5194/amt-7-3633-2014, 2014.

Gurubaran, S., Rajaram, R., Nakamura, T., and Tsuda, T.: Interannual variability of diurnal tide in the tropical mesopause region: A signature of the El Nino-Southern Oscillation (ENSO), Geophys. Res. Lett., 32, 13805, doi:10.1029/2005GL022928, 2005.

Hagan, M. and Forbes, J.: Migrating and nonmigrating diurnal tides in the middle and upper atmosphere excited by tropospheric latent heat release, J. Geophys. Res., 107, 4754, doi:10.1029/2001JD001236, 2002.

Hagan, M. E. and Roble, R. G.: Modeling diurnal tidal variability with the National Center for Atmospheric Research thermosphere-ionosphere-mesosphere-electrodynamics general circulation model, J. Geophys. Res., 106, 24869-24882, doi:10.1029/2001JA000057, 2001.

Hagan, M. E., Maute, A., Roble, R. G., Richmond, A. D., Immel, T. J., and England, S. L.: Connections between deep tropical clouds and the Earth's ionosphere, Geophys. Res. Lett., 34, L20109, doi:10.1029/2007GL030142, 2007.

Häusler, K. and Lühr, H.: Nonmigrating tidal signals in the upper thermospheric zonal wind at equatorial latitudes as observed by CHAMP, Ann. Geophys., 27, 2643-2652, doi:10.5194/angeo27-2643-2009, 2009.

Huang, F. T., McPeters, R. D., Bhartia, P. K., Mayr, H. G., Frith, S. M., Russell, J. M., and Mlynczak, M. G.: Temperature diurnal variations (migrating tides) in the stratosphere and lower mesosphere based on measurements from SABER on TIMED, J. Geophys. Res.-Atmos., 115, D16121, doi:10.1029/2009JD013698, 2010.

IMK-IAA MIPAS team: MIPAS/Envisat data, available at: https: //www.imk-asf.kit.edu/english/308.php, last access: $31 \mathrm{Au}-$ gust 2016.

Immel, T. J., Sagawa, E., England, S. L., Henderson, S. B., Hagan, M. E., Mende, S. B., Frey, H. U., Swenson, C. M., and Paxton, L. J.: Control of equatorial ionospheric morphol- ogy by atmospheric tides, Geophys. Res. Lett., 33, L15108, doi:10.1029/2006GL026161, 2006.

Jin, H., Miyoshi, Y., Fujiwara, H., and Shinagawa, H.: Electrodynamics of the formation of ionospheric wave number 4 longitudinal structure, J. Geophys. Res.-Space, 113, A09307, doi:10.1029/2008JA013301, 2008.

Kil, H., Oh, S.-J., Kelley, M. C., Paxton, L. J., England, S. L., Talaat, E., Min, K.-W., and Su, S.-Y.: Longitudinal structure of the vertical $\mathrm{E} \times \mathrm{B}$ drift and ion density seen from ROCSAT-1, Geophys. Res. Lett., 34, L14110, doi:10.1029/2007GL030018, 2007.

Laskar, F. I., Chau, J. L., Stober, G., Hoffmann, P., Hall, C. M., and Tsutsumi, M.: Quasi-biennial oscillation modulation of the middle- and high-latitude mesospheric semidiurnal tides during August-September, J. Geophys. Res.-Space, 121, 4869-4879, doi:10.1002/2015JA022065, 2016.

Li, X., Wan, W., Ren, Z., Liu, L., and Ning, B.: The variability of non-migrating tides detected from TIMED/SABER observations, J. Geophys. Res., 10793-10808, doi:10.1002/2015JA021577, 2015.

Lieberman, R. S., Riggin, D. M., Ortland, D. A., Nesbitt, S. W., and Vincent, R. A.: Variability of mesospheric diurnal tides and tropospheric diurnal heating during 1997-1998, J. Geophys. Res.Atmos., 112, D20110, doi:10.1029/2007JD008578, 2007.

Lieberman, R. S., Oberheide, J., and Talaat, E. R.: Nonmigrating diurnal tides observed in global thermospheric winds, J. Geophys. Res.-Space, 118, 7384-7397, doi:10.1002/2013JA018975, 2013.

Lieberman, R. S., Riggin, D. M., Ortland, D. A., Oberheide, J., and Siskind, D. E.: Global observations and modeling of nonmigrating diurnal tides generated by tide-planetary wave interactions, J. Geophys. Res., 120, 11419-11437, doi:10.1002/2015JD023739, 2015.

Liu, H.-L., Foster, B. T., Hagan, M. E., McInerney, J. M., Maute, A., Qian, L., Richmond, A. D., Roble, R. G., Solomon, S. C., Garcia, R. R., Kinnison, D., Marsh, D. R., Smith, A. K., Richter, J., Sassi, F., and Oberheide, J.: Thermosphere extension of the Whole Atmosphere Community Climate Model, J. Geophys. Res.-Space, 115, A12302, doi:10.1029/2010JA015586, 2010.

Liu, X., Xu, J., Yue, J., Liu, H. L., and Yuan, W.: Large winds and wind shears caused by the nonlinear interactions between gravity waves and tidal backgrounds in the mesosphere and lower thermosphere, J. Geophys. Res., 119, 7698-7708, doi:10.1002/2014JA020221, 2014.

Lübken, F.-J., Höffner, J., Viehl, T. P., Kaifler, B., and Morris, R. J.: First measurements of thermal tides in the summer mesopause region at Antarctic latitudes, Geophys. Res. Lett., 38, L24806, doi:10.1029/2011GL050045, 2011.

Marsh, D. R., Solomon, S. C., and Reynolds, A. E.: Empirical model of nitric oxide in the lower thermosphere, J. Geophys. Res.-Space, 109, A07301, doi:10.1029/2003JA010199, 2004.

Mayr, H. G. and Mengel, J. G.: Interannual variations of the diurnal tide in the mesosphere generated by the quasibiennial oscillation, J. Geophys. Res., 110, D10111, doi:10.1029/2004JD005055, 2005.

Mayr, H. G., Mengel, J. G., Talaat, E. R., Porter, H. S., and Chan, K. L.: Mesospheric non-migrating tides generated with planetary waves: I. Characteristics, J. Atmos. Sol.-Terr. Phy., 67, 959-980, doi:10.1016/j.jastp.2005.03.002, 2005a.

Mayr, H. G., Mengel, J. G., Talaat, E. R., Porter, H. S., and Chan, K. L.: Mesospheric non-migrating tides generated with planetary 
waves: II. Influence of gravity waves, J. Atmos. Sol.-Terr. Phy., 67, 981-991, doi:10.1016/j.jastp.2005.03.003, 2005b.

McLandress, C.: Interannual variations of the diurnal tide in the mesosphere induced by a zonal-mean wind oscillation in the tropics, Geophys. Res. Lett., 29, 1305, doi:10.1029/2001GL014551, 2002.

Moudden, Y. and Forbes, J. M.: A decade-long climatology of terdiurnal tides using TIMED/SABER observations, J. Geophys. Res.-Space, 118, 4534-4550, doi:10.1002/jgra.50273, 2013.

Mukhtarov, P. and Pancheva, D.: Global ionospheric response to nonmigrating DE3 and DE2 tides forced from below, J. Geophys. Res.-Space, 116, A05323, doi:10.1029/2010JA016099, 2011.

Nee, J. B.: Observations of non-migrating tides and ionospheric perturbations of $\mathrm{O}\left({ }^{1} \mathrm{D}\right)$ airglow by ISUAL instrument, Adv. Space Res., 54, 409-416, doi:10.1016/j.asr.2013.09.011, 2014.

Oberheide, J. and Forbes, J. M.: Tidal propagation of deep tropical cloud signatures into the thermosphere from TIMED observations, Geophys. Res. Lett., 35, L04816, doi:10.1029/2007GL032397, 2008a.

Oberheide, J. and Forbes, J. M.: Thermospheric nitric oxide variability induced by nonmigrating tides, Geophys. Res. Lett., 35, L16814, doi:10.1029/2008GL034825, 2008b.

Oberheide, J., Hagan, M. E., Roble, R. G., and Offermann, D.: Sources of nonmigrating tides in the tropical middle atmosphere, J. Geophys. Res.-Atmos., 107, 4567, doi:10.1029/2002JD002220, 2002.

Oberheide, J., Wu, Q., Ortland, D. A., Killeen, T. L., Hagan, M. E., Roble, R. G., Niciejewski, R. J., and Skinner, W. R.: Nonmigrating diurnal tides as measured by the TIMED Doppler interferometer: Preliminary results, Adv. Space Res., 35, 19111917, doi:10.1016/j.asr.2005.01.063, 2005.

Oberheide, J., Wu, Q., Killeen, T. L., Hagan, M. E., and Roble, R. G.: Diurnal nonmigrating tides from TIMED Doppler Interferometer wind data: Monthly climatologies and seasonal variations, J. Geophys. Res.-Space, 111, A10S03, doi:10.1029/2005JA011491, 2006.

Oberheide, J., Forbes, . J. M., Häusler, K., Wu, Q., and Bruinsma, S. L.: Tropospheric tides from 80 to $400 \mathrm{~km}$ : Propagation, interannual variability, and solar cycle effects, J. Geophys. Res., 114, D00I05, doi:10.1029/2009JD012388, 2009.

Oberheide, J., Forbes, J. M., Zhang, X., and Bruinsma, S. L.: Wavedriven variability in the ionosphere-thermosphere-mesosphere system from TIMED observations: What contributes to the wave 4?, J. Geophys. Res., 116, A01306, doi:10.1029/2010JA015911, 2011a.

Oberheide, J., Forbes, J. M., Zhang, X., and Bruinsma, S. L.: Climatology of upward propagating diurnal and semidiurnal tides in the thermosphere, J. Geophys. Res.-Space, 116, A11306, doi:10.1029/2011JA016784, 2011b.

Oberheide, J., Mlynczak, M. G., Mosso, C. N., Schroeder, B. M., Funke, B., and Maute, A.: Impact of tropospheric tides on the nitric oxide $5.3 \mu \mathrm{m}$ infrared cooling of the low-latitude thermosphere during solar minimum conditions, J. Geophys. Res., 118, 7283-7293, doi:10.1002/2013JA019278, 2013.

Oelhaf, H.: MIPAS Mission Plan, ESA Technical Note ENVISPPA-EOPG-TN-07-0073, available at: https://earth.esa.int/ web/sppa/documentation/envisat/mipas (last access: $31 \mathrm{Au}-$ gust 2018), 2008.
Pancheva, D. and Mukhtarov, P.: Strong evidence for the tidal control on the longitudinal structure of the ionospheric F-region, Geophys. Res. Lett., 37, L14105, doi:10.1029/2010GL044039, 2010.

Pancheva, D. and Mukhtarov, P.: Aeronomy of the Earth's Atmosphere and Ionosphere, chap. 2. Atmospheric Tides and Planetary Waves: Recent Progress Based on SABER/TIMED Temperature Measurements (2002-2007), 19-56, IAGA Special Sopron Book Series 2, Springer, edited by: Abdu, M. A., Pancheva, D., and Bhattacharyya, A., doi:10.1007/978-94-007-0326-1_2, 2011.

Pancheva, D., Mukhtarov, P., and Andonov, B.: Global structure, seasonal and interannual variability of the eastward propagating tides seen in the SABER/TIMED temperatures (2002-2007), Adv. Space Res., 46, 257-274, doi:10.1016/j.asr.2010.03.026, 2010.

Pancheva, D., Mukhtarov, P., and Smith, A. K.: Climatology of the migrating terdiurnal tide (TW3) in SABER/TIMED temperatures, J. Geophys. Res.-Space, 118, 1755-1767, doi:10.1002/jgra.50207, 2013.

Pedatella, N. M. and Liu, H.-L.: Tidal variability in the mesosphere and lower thermosphere due to the El Niño-Southern Oscillation, Geophys. Res. Lett., 39, L19802, doi:10.1029/2012GL053383, 2012.

Pedatella, N. M., Forbes, J. M., and Oberheide, J.: Intra-annual variability of the low-latitude ionosphere due to nonmigrating tides, Geophys. Res. Lett., 35, L18104, doi:10.1029/2008GL035332, 2008.

Pedatella, N. M., Hagan, M. E., and Maute, A.: The comparative importance of DE3, SE2, and SPW4 on the generation of wavenumber-4 longitude structures in the low-latitude ionosphere during September equinox, Geophys. Res. Lett., 39, L19108, doi:10.1029/2012GL053643, 2012.

Picone, J., Hedin, A., Drob, D., and Aikin, A.: NRLMSISE00 empirical model of the atmosphere: Statistical comparisons and scientific issues, J. Geophys. Res., 107, 1468, doi:10.1029/2002JA009430, 2002.

Ribstein, B., Achatz, U., and Senf, F.: The interaction between gravity waves and solar tides: Results from 4-D ray tracing coupled to a linear tidal model, J. Geophys. Res., 120, 6795-6817, doi:10.1002/2015JA021349, 2015.

Scherliess, L., Thompson, D. C., and Schunk, R. W.: Longitudinal variability of low-latitude total electron content: Tidal influences, J. Geophys. Res.-Space, 113, A01311, doi:10.1029/2007JA012480, 2008.

Senf, F. and Achatz, U.: On the impact of middle-atmosphere thermal tides on the propagation and dissipation of gravity waves, J. Geophys. Res.-Atmos., 116, D24110, doi:10.1029/2011JD015794, 2011.

Shepherd, G. G.: Thermospheric observations of equatorial wavenumber 4 density perturbations from WINDII data, Geophys. Res. Lett., 38, L08801, doi:10.1029/2011GL046986, 2011.

Shepherd, M. G., Shepherd, G. G., and Cho, Y.-M.: Longitudinal variability of thermospheric temperatures from WINDII $\mathrm{O}\left({ }^{1} \mathrm{~S}\right)$ dayglow, J. Geophys. Res.-Space, 117, A10302, doi:10.1029/2012JA017777, 2012.

Smith, A. K., Marsh, D. R., and Szymczak, A. C.: Interaction of chemical heating and the diurnal tide in the mesosphere, J. Geophys. Res.-Atmos., 108, 4164, doi:10.1029/2002JD002664, 2003. 
Talaat, E. R. and Lieberman, R. S.: Direct observations of nonmigrating diurnal tides in the equatorial thermosphere, Geophys. Res. Lett., 37, L04803, doi:10.1029/2009GL041845, 2010.

Teitelbaum, H. and Vial, F.: On tidal variability induced by nonlinear interaction with planetary waves, J. Geophys. Res., 96, 14169-14178, doi:10.1029/91JA01019, 1991.

Thayaparan, T.: The terdiurnal tide in the mesosphere and lower thermosphere over London, Canada $\left(43^{\circ} \mathrm{N}, 81^{\circ} \mathrm{W}\right)$, J. Geophys. Res., 102, 21695-21708, doi:10.1029/97JD01839, 1997.

Truskowski, A. O., Forbes, J. M., Zhang, X., and Palo, S. E.: New perspectives on thermosphere tides: 1 . Lower thermosphere spectra and seasonal-latitudinal structures, Earth Planet. Space, 66, 136, doi:10.1186/s40623-014-0136-4, 2014.

von Clarmann, T., Höpfner, M., Kellmann, S., Linden, A., Chauhan, S., Funke, B., Grabowski, U., Glatthor, N., Kiefer, M., Schieferdecker, T., Stiller, G. P., and Versick, S.: Retrieval of temperature, $\mathrm{H}_{2} \mathrm{O}, \mathrm{O}_{3}, \mathrm{HNO}_{3}, \mathrm{CH}_{4}, \mathrm{~N}_{2} \mathrm{O}, \mathrm{ClONO}_{2}$ and $\mathrm{ClO}$ from MIPAS reduced resolution nominal mode limb emission measurements, Atmos. Meas. Tech., 2, 159-175, doi:10.5194/amt-2-159-2009, 2009.

Wang, D. Y., Ward, W. E., Shepherd, G. G., and Wu, D.-L.: Stationary Planetary Waves Inferred from WINDII Wind Data Taken within Altitudes 90-120 km during 1991-96, J. Atmos. Sci., 57, 1906-1918, 2000.

Ward, W. E., Fomichev, V. I., and Beagley, S.: Nonmigrating tides in equinox temperature fields from the Extended Canadian Middle Atmosphere Model (CMAM), Geophys. Res. Lett., 32, L03803, doi:10.1029/2004GL021466, 2005.

Williams, C. R. and Avery, S. K.: Diurnal nonmigrating tidal oscillations forced by deep convective clouds, J. Geohys. Res., 101, 4079-4091, doi:10.1029/95JD03007, 1996.

Wu, Q., Ortland, D. A., Solomon, S. C., Skinner, W. R., and Niciejewski, R. J.: Global distribution, seasonal, and interannual variations of mesospheric semidiurnal tide observed by TIMED TIDI, J. Atmos. Sol.-Terr. Phy., 73, 2482-2502, doi:10.1016/j.jastp.2011.08.007, 2011.

Xu, J., Smith, A. K., Liu, H.-L., Yuan, W., Wu, Q., Jiang, G., Mlynczak, M. G., Russell, J. M., and Franke, S. J.: Seasonal and quasi-biennial variations in the migrating diurnal tide observed by Thermosphere, Ionosphere, Mesosphere, Energetics and Dynamics (TIMED), J. Geophys. Res., 114, 13107, doi:10.1029/2008JD011298, 2009.
Xu, J., Smith, A. K., Wang, W., Jiang, G., Yuan, W., Gao, H., Yue, J., Funke, B., López-Puertas, M., and Russell, J. M.: An observational and theoretical study of the longitudinal variation in neutral temperature induced by aurora heating in the lower thermosphere, J. Geohys. Res., 118, 7410-7425, doi:10.1002/2013JA019144, 2013.

Yue, J., Xu, J., Chang, L. C., Wu, Q., Liu, H.-L., Lu, X., and Russell, J.: Global structure and seasonal variability of the migrating terdiurnal tide in the mesosphere and lower thermosphere, J. Atmos. Sol.-Terr. Phy., 105, 191-198, doi:10.1016/j.jastp.2013.10.010, 2013.

Zhang, L., Jakob, D. J., Bowman, K. W., Logan, J. A., Turquety, S., Hudman, R. C., Li, Q., Beer, R., Worden, H. M., Worden, J. R., Rinsland, C. P., Kulawik, S. S., Lampel, M. C., Shephard, M. W., Fisher, B. M., Eldering, A., and Avery, M. A.: OzonCO correlations determined by the TES satellite instrument in continental outflow regions, Geophys. Res. Lett., 33, L18804, doi:10.1029/2006GL026399, 2006.

Zhang, X., Forbes, J. M., Hagan, M. E., Russell, J. M., Palo, S. E., Mertens, C. J., and Mlynczak, M. G.: Monthly tidal temperatures 20-120 km from TIMED/SABER, J. Geophys. Res., 111, A10S08, doi:10.1029/2005JA011504, 2006.

Zhang, X., Forbes, J. M., and Hagan, M. E.: Longitudinal variation of tides in the MLT region: 1. Tides driven by tropospheric net radiative heating, J. Geophys. Res.-Space, 115, A06316, doi:10.1029/2009JA014897, 2010a.

Zhang, X., Forbes, J. M., and Hagan, M. E.: Longitudinal variation of tides in the MLT region: 2. Relative effects of solar radiative and latent heating, J. Geophys. Res.-Space, 115, A06317, doi:10.1029/2009JA014898, 2010b.

Zhu, X., Yee, J.-H., Talaat, E. R., Mlynczak, M., Gordley, L., Mertens, C., and Russell III, J. M.: An algorithm for extracting zonal mean and migrating tidal fields in the middle atmosphere from satellite measurements: Applications to TIMED/SABERmeasured temperature and tidal modeling, J. Geophys. Res., 110, D02105, doi:10.1029/2004JD004996, 2005. 